\title{
Extrasynaptic neurotransmission in the modulation of brain function. Focus on the striatal neuronal-glial networks
}

\section{Kjell Fuxe ${ }^{1}{ }^{*}$, Dasiel O. Borroto-Escuela ${ }^{1}$, Wilber Romero-Fernandez ${ }^{1}$, Zaida Diaz-Cabiale $^{2}$, Alicia Rivera ${ }^{3}$, Luca Ferraro ${ }^{4}$, Sergio Tanganelli ${ }^{4}$, Alexander O. Tarakanov ${ }^{5}$, Pere Garriga ${ }^{6}$, José Angel Narváez ${ }^{2}$, Francisco Ciruela ${ }^{7}$, Michele Guescini $^{8}$ and Luigi F. Agnati ${ }^{9}$}

1 Department of Neuroscience, Karolinska Institutet, Stockholm, Sweden

2 Department of Physiology, School of Medicine, University of Málaga, Málaga, Spain

${ }^{3}$ Department of Cell Biology, Faculty of Sciences, University of Málaga, Málaga, Spain

${ }^{4}$ Pharmacology Section, Department of Clinical and Experimental Medicine, University of Ferrara, Ferrara, Italy

${ }^{5}$ Russian Academy of Sciences, St. Petersburg Institute for Informatics and Automation, Saint Petersburg, Russia

${ }^{6}$ Departament d'Enginyeria Química, Centre de Biotecnologia Molecular, Universitat Politècnica de Catalunya, Barcelona, Spain

7 Unitat de Farmacologia, Departament Patologia i Terapèutica Experimental, Universitat de Barcelona, Barcelona, Spain

${ }^{8}$ Department of Biomolecular Sciences, University of Urbino "CarloBo," Urbino, Italy

${ }^{9}$ IRCCS Lido, Venice, Italy

\section{Edited by:}

Francisco Fernandez De-Miguel, Universidad Nacional Autonoma de Mexico, Mexico

\section{Reviewed by:}

Francisco Fernandez De-Miguel, Universidad Nacional Autonoma de Mexico, Mexico

Teresa Giraldez, University Hospital NS Candelaria, Spain

\section{${ }^{*}$ Correspondence:}

Kjell Fuxe, Department of

Neuroscience, Karolinska Institutet, Retzius väg 8, 17177 Stockholm,

Sweden.

e-mail: kjell.fuxe@ki.se
Extrasynaptic neurotransmission is an important short distance form of volume transmission (VT) and describes the extracellular diffusion of transmitters and modulators after synaptic spillover or extrasynaptic release in the local circuit regions binding to and activating mainly extrasynaptic neuronal and glial receptors in the neuroglial networks of the brain. Receptor-receptor interactions in G protein-coupled receptor (GPCR) heteromers play a major role, on dendritic spines and nerve terminals including glutamate synapses, in the integrative processes of the extrasynaptic signaling. Heteromeric complexes between GPCR and ion-channel receptors play a special role in the integration of the synaptic and extrasynaptic signals. Changes in extracellular concentrations of the classical synaptic neurotransmitters glutamate and GABA found with microdialysis is likely an expression of the activity of the neuron-astrocyte unit of the brain and can be used as an index of VT-mediated actions of these two neurotransmitters in the brain. Thus, the activity of neurons may be functionally linked to the activity of astrocytes, which may release glutamate and GABA to the extracellular space where extrasynaptic glutamate and GABA receptors do exist. Wiring transmission (WT) and VT are fundamental properties of all neurons of the CNS but the balance between $\mathrm{WT}$ and $\mathrm{VT}$ varies from one nerve cell population to the other. The focus is on the striatal cellular networks, and the WT and VT and their integration via receptor heteromers are described in the GABA projection neurons, the glutamate, dopamine, 5hydroxytryptamine $(5-\mathrm{HT})$ and histamine striatal afferents, the cholinergic interneurons, and different types of GABA interneurons. In addition, the role in these networks of VT signaling of the energy-dependent modulator adenosine and of endocannabinoids mainly formed in the striatal projection neurons will be underlined to understand the communication in the striatal cellular networks.

Keywords: extrasynaptic, neurotransmission, receptor-receptor interactions, volume transmission, G protein coupled receptors, striatal networks, heteromers, wiring transission

\section{INTRODUCTION}

The discovery of the central dopamine (DA), noradrenaline (NA), and 5-hydroxytryptamine (5-HT) pathways was made in 19631965 with the Falck-Hillarp technique (Falck et al., 1962) and represented my thesis work (see Fuxe, 1965; Fuxe et al., 2007a). These monoamine brainstem systems were unique in having ascending monosynaptic connections with the tel- and diencephalon including the cerebral cortex giving rise to global networks all over the tel- and diencephalon with collaterals forming terminal networks in the lower brainstem. They also produced descending connections to the spinal cord innervating its entire gray matter at all rostro-caudal levels. The locus coeruleus built up of NA cell bodies could even send out both ascending and descending NA projections as well as NA projections to the cerebellum resulting in a global modulation of the entire central nervous system (CNS) from a single nerve cell nucleus through the vast NA nerve terminal plexa formed. This unique architecture of the central monoamine neurons gave thoughts on if in fact these neurons communicated via synaptic transmission.

In 1969-1970 we observed the appearance of extraneuronal diffuse (catecholamine) fluorescence around midbrain DA nerve cell bodies after amphetamine, a catecholamine releasing drug, 
in reserpine-nialamide-L-dopa treated rats (Fuxe and Ungerstedt, 1970a). In parallel, a similar diffuse extraneuronal 5-HT fluorescence was found among the 5-HT cell bodies of the dorsal raphe nucleus after 5-HT uptake blockade with chlorimipramine in reserpine and nialamide pretreated rats (Fuxe et al., 1970b). We did not, in the beginning, understand these observations but we asked the question if they reflected a communication different from the synaptic one. We also observed that microinjected DA in the striatum could diffuse (Ungerstedt et al., 1969). This observation was confirmed in 1992 with DA immunohistochemistry (Agnati et al., 1992).

Such observations and the existence of global monoamine terminal networks together with several other observations in the literature, especially the demonstration of non-junctional monoamine varicosities by Descarries et al. (1975) led Agnati et al. (1986) to propose the concept of volume transmission (VT). The major observation in this paper was the failure to see a correlation between the regional distribution of central encephalin and beta-endorphin immunoreactive terminal networks and of central opioid receptors. The existence of two main modes of intercellular communication in the CNS was proposed and called wiring transmission (WT; prototype: synaptic transmission) and VT (Agnati et al., 1986). The major criterion for this classification was the different characteristics of the communication channel with physical boundaries well delimited in the case of WT (axons and their synapses; gap junctions) (Froes et al., 1999; Ozog et al., 2002; Bennett et al., 2003; Duan et al., 2004; Schools et al., 2006) but not in the case of VT (the extracellular fluid (ECF) filled tortuous channels of the extracellular space (ECS) and the cerebrospinal fluid (CSF) filled ventricular space and sub-arachnoidal space). Of special importance for us was the demonstration of relative transmitter-receptor mismatches in the opioid peptide systems (Agnati et al., 1986; Fuxe et al., 1988c). In parallel, Descarries et al. (1991) developed his concept of diffuse transmission based on the existence of non-junctional monoamine varicosities which is in line with our concept of VT.

\section{VOLUME TRANSMISSION}

Volume transmission is defined as "A widespread mode of intercellular communication that occurs in the ECF and in the CSF of the CNS with VT signals moving from source to target cells via energy gradients leading to diffusion and convection." The communication channels are diffuse; there exists a reserved or private communication mainly mediated via high affinity $G$ proteincoupled receptors (GPCRs); the safety of communication is low as a result of the diffusion process and the connectivity of the diffusion channels is dynamic from open to closed (see Fuxe and Agnati, 1991b; Agnati et al., 2000, 2006; Chen et al., 2002a; Fuxe et al., 2005, 2007a). There may exist three subtypes of VT: extrasynaptic fast VT (100 msec-sec), the long-distance slow VT (sec-hour), and the roamer type of VT-mediated via microvesicles (Agnati et al., 2010a; Fuxe et al., 2010a). Two modes of microvesicle release exist namely the exocytosis of internal luminal vesicles formed in the multivesicular bodies (exosomes) and the direct budding of small vesicles from the plasma membrane (shedding vesicles). Exosomes represent a subclass of such membrane vesicles which are released by cells upon fusion of the multivesicular bodies with the plasma membrane (Guescini et al., 2012).
Migration (diffusion and flow) of VT signals (transmitters, modulators, trophic factors, ions, etc.) takes place via concentration gradients, temperature gradients, and pressure waves.

Wiring transmission, the prototype being synaptic transmission is characterized by private channels (axons) and a private or reserved communication mainly mediated by ion-channel receptors and operates with high speed (msecs); the safety is high and the connectivity static and/or dynamic. One subtype of WT is the gap junction the communication of which has no privacy but can be described as having a broadcasting character.

The overall evidence indicates that vast majority of neurons possess the fundamental property of operating via both WT and VT but the balance between them varies from one nerve cell population to the other and with the dynamic state of the neuron. In contrast, glial cells and endothelial cells operate exclusively via VT. The source of the neuronal VT signal is mainly from nerve terminal networks but also from soma and dendrites.

The ECS is characterized by three parameters (see Nicholson and Sykova, 1998). Volume fraction is the relative size of the ECS compared to total brain tissue volume. Tortuosity is the increase in path length that is imposed on a migrating molecule by cellular structures and extracellular matrix components. These two parameters are unit-less. Then, there is the clearance which is a constant that reflects the removal or disappearance of a compound from the ECS, and has the unit per second. Also a mathematical theory of diffusion in the brain with dual-probe microdialysis has been developed and the theory was able to fit the experimental data (Chen et al., 2002b; Hoistad et al., 2002). The diffusion of ${ }^{3} \mathrm{H}$-mannitol using dual-probe microdialysis enabled a quantification of the classical diffusion parameters discussed above in the rat striatum.

\section{EXTRASYNAPTIC TRANSMISSION (A SUBTYPE OF VT)}

Extrasynaptic VT including perisynaptic transmission is linked to synaptic transmission and likely often takes place due to incomplete diffusion barriers (transmitter spillover or extrasynaptic release) with the synaptic transmitter reaching extrasynaptic domains of the pre and postsynaptic membrane of the synapse, the astroglia, and even adjacent synapses (Vizi, 1980; Vizi et al., 2004; Harvey and Svoboda, 2007). Other terminal varicosities fail to form synapses and are asynaptic and release the transmitter directly into the ECS. This subtype of VT operates at the local circuit level mainly through binding and activation of extrasynaptic high affinity GPCRs on neuronal and glial cells (Carmignoto, 2000) but also receptor tyrosine kinase, ion-channel receptors, and cytokine receptors are involved in linking together regulation of gene expression, firing and trophism, blood flow, and immune responses in the neuroglial networks of the CNS. In this integrative process, receptor-receptor interactions in different types of receptor heteromers play a major role (see Fuxe et al., 2007a; Borroto-Escuela et al., 2010, 2011; Fuxe et al., 2010a,b; Kenakin et al., 2010).

\section{Extrasynaptic glutamate and GABA transmission}

The classical synaptic transmitters glutamate and GABA can be measured extracellularly with microdialysis (see Ferraro et al., 1998) and reach receptors at surrounding astroglia, and at neighboring synapses, modulating the synaptic transmission 
process and leading to astroglial release of glutamate being dependent on the efficacy of the glial and neuronal transporters of glutamate (see Del Arco et al., 2003; Fuxe et al., 2007b). Thus, the extrasynaptic transmission can be blocked by glial sheaths and extracellular matrix through their formation of diffusion barriers e.g., perineuronal nets and the astrocytic isolation may change over a short or long time-scale. The fate of escaping transmitters is determined not only by the transporters but also by inactivating enzymes. It seems clear that one and the same transmitter, like glutamate and GABA, can be released both as a synaptic signal and as an extrasynaptic signal producing a rapid form of VT.

As an extrasynaptic signal, glutamate can increase calcium mediated astroglial glutamate release via activation of astroglial metabotropic glutamate receptors which may involve both exocytosis and transporters (Del Arco et al., 2003). The increase of extracellular glutamate levels can be detected by microdialysis (Del Arco et al., 2003). In this way, metabolic and trophic adjustments can develop in the neuron-astrocytic unit upon activation of its glutamate synapses including increases in blood flow.

Recently, imaging of extrasynaptic glutamate VT has been accomplished by Okubo et al. (2010) during synaptic activity. The glutamate optical sensor (EOS) is a hybrid-type fluorescent indicator consisting of the glutamate-binding domain of the AMPAR subunit GluR2 and a fluorescent small molecule conjugated near the glutamate-binding pocket. EOS changes its fluorescence intensity upon binding of glutamate, for which it has both high affinity and high selectivity. The electron microscopy analysis indicated that labeled K716A-EOS was distributed throughout the extracellular surface of cells without any accumulation in the synaptic cleft, and that $>97 \%$ of the indicator molecules were present extrasynaptically. They imaged the K716A-glutamate optical signal (EOS) fluorescence at various depths of the brain slice in response to parallel fiber stimulation. The magnitude and duration of the extrasynaptic dynamics were adequate for the activation of the extrasynaptic glutamate receptors and crosstalk between synapses was established (Okubo et al., 2010; Okubo and Iino, 2011).

\section{Extrasynaptic 5-HT transmission}

Double immunolabeling of 5-HT immunoreactivity (IR) in nerve terminals and 5-HT2A IR in apical dendritic shafts of pyramidal nerve cells of the cerebral cortex have demonstrated their relationships (Jansson et al., 2001). In the horizontal sections, the mean distance from a 5-HT2A-IR apical dendrite to the closest 5-HT-IR terminal-like varicosity was calculated to be $7.7 \mu \mathrm{m}$. Thus, these observations indicate the existence of an extrasynaptic 5-HT2A mediated VT in the cerebral cortex. The 5-HT terminal-extrasynaptic 5-HT receptor subtype relationships have been reviewed by Jansson et al. (2002). These observations are in line with the early work of Fuxe et al. (1970b) on 5-HT diffusion in the raphe dorsalis and of Descarries et al. (1975) on the existence of large numbers of non-junctional 5-HT terminal varicosities which vary from one region to the other (Descarries and Mechawar, 2000). De-Miguel and Trueta (2005) have also demonstrated extrasynaptic exocytosis of 5-HT involving multiple mechanisms including both clear vesicles and dense core vesicles. Somatic exocytosis of 5-HT in cultured leech neurons takes place exclusively from dense core vesicles (Trueta et al., 2003). It is of substantial interest that 5-HT released from cultured leech neurons produces inhibition of the firing of the 5-HT neurons through activation of 5-HT autoreceptors (Cercos et al., 2009).

\section{Extrasynaptic DA transmission}

Dopamine transmitter/D1 receptor mismatches have been observed by receptor autoradiography and dual immunolabeling of the pre and postjunctional structures of the ascending DA neurons (Fuxe et al., 1988a,b). Thus, release of DA is often observed not to be in strict contiguity with postsynaptic membranes, and a high incidence of non-junctional DA terminal varicosities is observed in the neostriatum (Descarries et al., 1996; Descarries and Mechawar, 2000). The ultrastructural analysis, based on transmitter and receptor immunocytochemistry, has repeatedly demonstrated short distance transmitter/receptor mismatches for the DA transmitter with the major part of the D1 and D2 receptor labeling being outside the DA synapses in the local striatal circuits, in which the DA synapses and/or non-junctional DA terminals are found (Dana et al., 1989; Levey et al., 1993; Sesack et al., 1994; Smiley et al., 1994; Hersch et al., 1995, 1997; Yung et al., 1995; Caille et al., 1996; for review see Jansson et al., 2002). The evidence therefore indicates that DA mainly acts as a VT transmitter being directly released into the ECF or reaching it via leaking DA synapses (Fuxe and Agnati, 1991a,b; Zoli and Agnati, 1996; Fuxe et al., 2007a). Rice and Cragg (2008) have modeled DA spillover after quantal release based on a large number of experimental data. In the updated DA synapse the DA release is unconstrained by the extrasynapic dopamine transporter (DAT), the diffusion process being too fast for the DAT which mainly increases clearance of DA and thus its half-life. A cloud of DA is formed and can reach the extrasynaptic DA receptors which are in majority. Thus, the primary mode of DA communication is VT. The effective radius for high affinity DA receptors is $7-8 \mu \mathrm{m}$ which is compatible with extrasynaptic VT. This is the extrasynaptic short distance subtype of VT. The spheres obtained would encompass tens to thousands of synapses and the action of DA involves the activation of extrasynaptic receptors on terminals, dendrites, soma, and axons.

The D2 receptors are of special interest since the $\mathrm{KiH}$ (the dissociation constant of the high affinity state of the receptor) value for DA at $\left[{ }^{3} \mathrm{H}\right]$ raclopride-labeled D2-like receptors in dorsal striatum was $12 \mathrm{nM}$ (Marcellino et al., 2011), and this can help explain PET findings that amphetamine-induced increases in DA release can produce an up to $50 \%$ decrease of $\left[{ }^{11} \mathrm{C}\right]$ raclopride binding in the dorsal striatum in vivo (Dewey et al., 1993; Laruelle, 2000; Seneca et al., 2006). These combined results give indications for the existence of striatal D2-like receptor-mediated extrasynaptic form of DA VT at the local circuit level in vivo in the human striatum (Marcellino et al., 2011). However, in Parkinson disease also a long-distance form of DA VT likely develops due to the development of DA receptor supersensitivity (Fuxe et al., 2003, 2010c). Thus, larger distances of diffusion of released DA can still maintain DA transmission since the supersensitive DA receptors are sensitive to very low concentrations of DA. Parkinson disease develops when too few DA terminal networks remain and distance from the DA release site to the vast majority of DA becomes too distant for DA receptor activation (Fuxe, 1979). At this stage 1-DOPA 
treatment and/or D2 receptor agonist treatment are introduced producing antiparkinson actions through activation of the supersensitive striatal DA (Fuxe et al., 2003,2010c). Thus, this treatment substitutes for the loss of DA VT in Parkinson disease.

\section{Extrasynaptic noradrenaline transmission}

The low synaptic incidence of cortical NA nerve terminal plexa has been demonstrated in the rat and monkey being in the order of 7-18\% (Seguela et al., 1990; Aoki et al., 1998), which is clearly lower than the synaptic incidence in cortical (56-92\%) and neostriatal (30-40\%) DA nerve terminal plexa in the rat (Descarries and Mechawar, 2000).

The relationships of NA nerve terminal to extrasynaptic adrenergic receptors have been established (Aoki et al., 1998). Dual immunolabeling of $\beta$-adrenergic receptors and CA nerve terminal networks in the cerebral cortex using electron microscopic immunocytochemistry have demonstrated membrane contacts between CA nerve terminals rich in vesicles and $\beta$-adrenergic IR astrocytes, giving evidence for neuroglia communication via VT (Aoki, 1992; Aoki and Pickel, 1992). It was of interest that these $\beta$-adrenergic receptor IR astrocytes also surrounded asymmetric axo-spinous synapses, where the astroglia $\beta$-adrenergic receptors may modulate e.g., glutamate spillover by modulating the activity of the glial glutamate transporters and/or the permeability of the astroglial gap junctions, and thus the sphere of astroglia activation (Aoki, 1992). In another study with similar techniques, Aoki et al. (1998) also demonstrated that prefrontal NA terminal networks can interact via VT with astroglia, dendritic shafts, and axon terminals through their $\alpha 2$-adrenergic receptors as well as via synaptic transmission through $\alpha 2$-adrenergic receptors located in postsynaptic membranes at spines of pyramidal cells.

A dysfunction of the locus coeruleus NA system together with meso-cortical DA system may contribute to attention deficit hyperactivity disorders (ADHD). High levels of D4 IR have been found in many cortical regions like motor, somatosensory, temporal association, and cingulate cortices with synaptic and extrasynaptic locations (Rivera et al., 2008). In addition, these receptors have a high affinity for NA (Newman-Tancredi et al., 1997), and the D4 IR is in fact more closely related to the widespread NA terminal plexa than the restricted DA terminal plexa (mainly limbic cortex).

It should therefore be considered that CAs may be released from the cortical NA nerve terminals and may, via extrasynaptic VT, reach and activate dopamine D4 receptors located on pyramidal and non-pyramidal nerve cells in many regions of the cerebral cortex (Rivera et al., 2008). Thus, methylphenidate drugs used in the treatment of ADHD are known to release DA and NA and may therefore act in part by restoring synaptic and extrasynaptic DA and NA transmission in the cerebral cortex (see Smiley et al., 1992; Smiley et al., 1997) involving not only classical D1, D2, and adrenergic receptors but also D4 receptors which may be activated also by extrasynaptic NA transmission (Rivera et al., 2008).

\section{Extrasynaptic acetylcholine transmission}

Widespread plexa of cholinergic nerve terminals exist in the CNS with high densities especially in the striatum and have, like the NA and 5-HT nerve terminal networks, been found to have a low synaptic incidence in the cerebral cortex and neostriatum and thus mainly operate via volume (diffuse) transmission (Descarries and Mechawar, 2000). This was in the beginning found to be surprising since acetylcholinesterase was believed to quickly degrade acetylcholine in the synaptic cleft. The explanation is that this effective degradation is performed by the A12 isoform of acetylcholinesterase while brain acetylcholinesterase mainly consists of the G4 isoform (Gisiger and Stephens, 1988) as discussed by Descarries et al. (1997). Thus, the extrasynaptic form of VT can develop but long distance VT is prevented by the brain acetylcholinesterase.

\section{Extracellular monoamine and acetylcholine transmission and vesicular glutamate transporters}

Large numbers of monoamine and acetylcholine neurons have been shown to contain a vesicular glutamate transporter (VGLUT; see El Mestikawy et al., 2011) which may have relevance for extrasynaptic monoamine and acetylcholine transmission. Thus, the VGLUT is mainly driven by the vesicular transmembrane potential component of the proton gradient which leads to more acidified vesicles. This allows the vesicular monoamine transporter (VMAT2) and vesicular acetylcholine transporters (VAChT) to accumulate higher amounts of monoamines and acetylcholine, respectively since these transporters are mainly dependent on the $\mathrm{pH}$ gradient over the vesicular membrane (El Mestikawy et al., 2011). Three types of VGLUT exist namely VGLUT1, VGLUT2, and VGLUT3 and are present in central monoamine and acetylcholine neurons besides GABA and glutamate neurons. This has led to discussions on whether glutamate can be co-transmitter in these neurons enabling glutamate co-release. It has been especially discussed if glutamate in DA neurons is linked to the formation of junctional DA terminals (synapses; Descarries et al., 2008). However, it appears to be largely a developmental feature since double labeling of tyrosine hydroxylase (TH) and VGLUT2 in DA terminals is hardly observed in adult rats. It is of substantial interest that a heterogeneity in DA, 5-HT and acetylcholine terminals may exist with regard to co-expression of VGLUTs and VMAT2 or VAChT (see El Mestikawy et al., 2011). In some of them it seems possible that there may exist synaptic vesicles containing both VMAT2 and VGLUT2 (DA varicosity), VMAT2 and VGLUT3 (5-HT varicosity), and VAChT and VGLUT3 (acetylcholine varicosity). In fact, evidence exists that the presence of VGLUT can lead to so-called vesicular synergy meaning increased accumulation of the primary transmitter (monoamine or acetylcholine; Gras et al., 2008; Amilhon et al., 2010; Hnasko et al., 2010). The molecular mechanism for vesicular synergy is likely that the VGLUT is driven by the vesicular transmembrane potential with the accumulation of glutamate (acid) leading to an acidification of the vesicle. In view of the fact that the VMAT2 and VAChT is dependent on a $\mathrm{pH}$ gradient over the vesicular membrane this will allow increased amounts of monoamines and acetylcholine to accumulate in the monoamine and acetylcholine vesicles (El Mestikawy et al., 2011). This is likely of relevance for the extrasynaptic monoamine and acetylcholine transmission since higher amounts of transmitter can be released into the ECF directly or via synaptic spillover from these varicosities and a larger volume can be reached with sufficient concentrations of monoamines and 
acetylcholine to activate their extrasynaptic high affinity receptors. Increased quantal contents of vesicles of the primary transmitter with increased release has in fact been shown for VGLUT3 in 5-HT and acetylcholine neurons (Gras et al., 2008; Amilhon et al., 2010). Thus, an increase in extrasynaptic transmission is obtained. The VGLUT research will represent an exciting field for understanding VT in the CNS.

\section{LONG DISTANCE VT}

1. Long distance DA VT up to $30-50 \mu \mathrm{m}$ may also exist in the striatum of the intact rat. Thus, we have observed substantial D1-TH terminal mismatches (in the maximal range of 30-50 $\mu \mathrm{m}$ ) in the nucleus accumbens shell with D1 rich areas surrounded by highly dense DA nerve terminal plexa (Jansson et al., 1999). It may be that here the existence of energy gradients, especially temperature gradients created by the uncoupling protein 2 (UCP2) in the DA terminal regions, increase the migration of DA into the D1 rich and TH poor region (Rivera et al., 2006). UCP2 produces a disappearance of the $\mathrm{H}+$ gradient in the mitochondria with generation of heat leading to a temperature gradient vs. the D1 receptor rich cellular network. This may lead to mass movement of the ECF (flow) carrying DA into the mismatch region which is more rapid than DA diffusion alone. It should be mentioned that DA can also be released into the portal blood vessels from the tuberoinfundibular DA neurons (Fuxe, 1963, 1964; Fuxe et al., 1967; MacLeod and Lehmeyer, 1974; Andersson et al., 1981) to activate the D2 receptors on the prolactin cells of the anterior pituitary. Thus, DA can act as a synaptic transmitter, VT transmitter, and as a hypothalamic hormone.

2. Long distance peptide VT and CSF VT

Peptide neurons likely operate via long distance VT with distances over $1 \mathrm{~mm}$ involving also flow in the CSF (Fuxe et al., 2010a). One of the best examples is CSF delivered beta-endorphin $(2500 \mathrm{pmol}$ in $5 \mu \mathrm{l}$ ) which could accumulate in nerve cell body subpopulations and their dendrites all over the paraventricular hypothalamus as seen 15 min after the CSF injection (Agnati et al., 1992; Bjelke and Fuxe, 1993). The likely mechanism is that beta-endorphin is internalized into discrete subependymal and periventricular nerve terminal plexa and then undergoes retrograde transport to the nerve cell bodies developing beta-endorphin IR. These results indicate that beta-endorphin CSF VT may exist which - via opioid receptors located on periventricular nerve terminal plexa - may become internalized and retrogradely transported to potentially modulate the gene expression and firing of such neurons (Agnati et al., 1992). Striatally microinjected beta-endorphin can also reach the CSF as an intact peptide as shown with mass-spectrometry (Hoistad et al., 2005). So, beta-endorphin may not only employ long distance diffusion in the ECF but also CSF mediated VT as a complementary communication pathway, to also reach and activate distant opioid receptors. These results are in line with the work of Duggan's group on beta-endorphin based on antibody microprobes (MacMillan et al., 1998). They observed that beta-endorphin IR could be detected in CSF and remote brain areas lacking beta-endorphin IR terminals, like the cerebral cortex,
60-90 min after the initial stimulation of the arcuate nucleus where the beta-endorphin cell bodies are located.

These results taken together give strong indications that betaendorphin could migrate for long distances in the ECF and CSF after its release from beta-endorphin IR nerve terminal networks.

These results are also of relevance for understanding cotransmission in monoamine neurons often containing neuropeptides (see book by Hökfelt et al., 1986). The release of neuropeptides may allow the monoamine neurons to send VT signals to cellular networks further away from the monoamine terminals. Peptides and proteins may have a high stability and/or act via active peptide fragments which make long distance VT possible involving also CSF VT (Fuxe et al., 2010a and see above). The temporal code of VT related to dynamic changes in release of transmitters is likely to exist especially at short distances, while with long distances of diffusion/convection observed with peptides/proteins the dynamic changes in VT modulating the wired networks may be less pronounced. However, it seems likely that peptide release may be exceptionally enhanced with burst firing based on the work of Lundberg (1991) indicating that longdistance peptides/protein VT can be markedly increased under specific physiological conditions.

In the case of monoamine/peptide co-storing neurons it thus seems likely that the co-released monoamines and peptides from the same nerve terminal networks only interact via receptorreceptor interactions in the range of short diffusion distances. At long distances the migrating peptides/proteins probably along preferential VT channels (paravascular ECF channels or ECF channels along myelinated fiber bundles) instead activate receptors which interact with receptors stimulated by transmitters belonging to other types of neurons.

\section{UNDERSTANDING THE ROLE OF EXTRASYNAPTIC AND LONG DISTANCE VT IN THE FUNCTIONAL MODULES (NEURONAL NETWORKS) OF THE CNS GIVING RISE TO THE NEURONAL CIRCUITS}

The neuronal-astroglial networks form functional modules which give rise to several outputs/efferents that is several types of axon bundles forming fiber tracts that influence in various ways other functional modules linked to it. The resulting activity changes in these functional modules will, by forming dynamic brain circuits, have an impact on brain function e.g., behavioral changes. A major role of the VT signals is to modulate the WT, especially the synaptic transmission, in the neuronal networks forming the functional modules. In this way, via changes in VT, it becomes possible for the same neuronal network to change the balance of activity in its different projection neurons to other functional modules (neuronal networks) and thus in their brain circuits and in brain function. The mechanism involved is likely the ability of the diffusing VT signals in ECF to upregulate and/or downregulate synaptic transmission in different parts of the neuronal network via activation of e.g., monoamine, acetylcholine, and/or peptide receptors mainly located in the local circuits of the neuronal-astroglial network. Both neuronal extrasynaptic and long distance VT signaling can be involved and the architecture of the diverse high affinity receptor distributions on the neurons and glia will determine the outcome on the balance of activity in the different types of projection neurons from the functional module. These neuronal VT 
signals can be released from terminal networks within the functional module with nerve cell bodies located outside the functional module or from interneurons within the module. Also the projection neurons of the module can mainly via recurrent collaterals give rise to VT signals. There also exists soma-dendritic extrasynaptic exocytosis of VT signals within the neurons of the module contributing inter alia to the activation and regulation of the high affinity soma-dendritic autoreceptors at this level (see De-Miguel and Trueta, 2005). Finally, VT signals arise also from the glial cells of the module like adenosine (Ferre and Fuxe, 2000) and kynurenic acid (Schwarcz and Pellicciari, 2002) from the astroglia. The major molecular mechanism appears to be the modulation of synaptic receptors through activation of extrasynaptic receptors by VT signals which modulate the synaptic receptors via allosteric receptor-receptor interactions in receptor heteromers built up of synaptic and extrasynaptic receptors (Agnati et al., 2010a; Fuxe et al., 2010a). The formation of receptor heteromers by synaptic ion-channel receptors like NMDA and GABA receptors and GPCRs have been demonstrated by Fang Liu and colleagues (see Liu et al., 2000; Lee et al., 2002; Liu et al., 2006). In addition, also VT signals can interact and integrate their signaling via GPCRGPCR interactions in heteromers e.g., A2A-D2 heteromers at the extrasynaptic level (Fuxe et al., 1998, 2010b).

\section{EXTRASYNAPTIC AND LONG DISTANCE VOLUME TRANSMISSION IN THE NEURONAL-ASTROGLIAL NETWORKS OF THE MATRIX OF THE DORSAL STRIATUM \\ Projection neurons}

The analysis of this striatal network gives a beautiful example of the interplay of synaptic transmission and VT in the regulation of the neuronal-astroglial networks of the CNS. Around 95\% of the nerve cells represent projection neurons, the so-called GABAergic medium spiny neurons (MSN). There exist mainly two subtypes: The enkephalin containing striato-pallidal GABA neurons (indirect pathway; external globus pallidus) and the dynorphin and substance $\mathrm{P}$ containing striato-entopeduncular (internal globus pallidus) and striato-nigral GABA neurons (direct pathway). The MSN GABA neurons give rise to axon collaterals which may have a significant feedback effect with a reduction of the overall activity in the striatal matrix through GABA synapses (Tepper et al., 2008).

Opioid peptides. The axon collaterals of the striato-pallidal GABA neurons forming junctional and non-junctional varicosities likely release enkephalins into ECF extrasynaptically or via synaptic spillover (Agnati et al., 1986; Fuxe et al., 1988c), to activate mu and delta opioid receptors located on terminals (mainly delta opioid receptors) and dendrites (mainly mu opioid receptors) of the striatal local circuits including the DA nerve terminals (Eghbali et al., 1987; Arvidsson et al., 1995). Enkephalin immunoreactive terminals in double immunolabeling experiments are closely associated with these two types of opioid receptors and therefore the enkephalin transmission likely mainly involves extrasynaptic VT (Arvidsson et al., 1995). It is of substantial interest that D1-mu-opioid receptor heteromers have been demonstrated in cellular models (Juhasz et al., 2008) and morphine induced locomotion requires D1 receptor activation (Hnasko et al., 2005). In view of the fact that the vast majority of the D1 receptors exist in the striato-entopeduncular/nigral GABA neurons (direct pathway) lacking D2 receptors one important function of the released enkephalins from the axon collaterals, and possibly dendrites of the striato-pallidal GABA neurons, may be to diffuse to and enhance signaling in the D1-mu-opioid receptor heteromer located in the dendrites of the direct pathway increasing its activity. D1 and mu opioid receptors are also co-located in the striatum (Juhasz et al., 2008). Thus, the extrasynaptic enkephalin signaling of the striatopallidal GABA neurons causing motor inhibition may inter alia facilitate cross-modulation of the adjacent neurons of the direct pathway which increases motor initiation. In this way the unbalance of activity in the two main efferent pathways will be reduced and assisting in counteracting excessive motor inhibition. There may exist also D4-mu opioid receptor heteromers in the striatum especially in the striatal islands (striosomes) where the D4 and mu opioid receptors are enriched and co-located (Gago et al., 2007; Fuxe et al., 2008c; Rivera et al., 2008) with D4 activation markedly antagonizing morphine induced transcription factor expression in the striatum (Gago et al., 2011).

In contrast, the dynorphin immunoreactive terminals of the direct pathway are in proximity with the dendritic kappa opioid receptors (Elde et al., 1995) likely representing a kappa opioid receptor-mediated extrasynaptic dynorphin transmission. It can be speculated that this partially represents a reciprocal regulation by the direct pathway of the indirect pathway, the striato-pallidal GABA neurons which are enriched in D2 receptors and may possess kappa opioid receptors. It seems likely that these dynorphin immunoreactive terminals also may contain substance $\mathrm{P}$ immunoreactivity (Bolam et al., 1983) and also operate via extrasynaptic substance $\mathrm{P}$ transmission. There does also exist a DA D1-D2 receptor heteromer signaling pathway in dynorphin/enkephalin MSN but they have a low incidence in the caudate putamen (Perreault et al., 2010; Hasbi et al., 2011).

Neurotensin peptides. The striatal NT tissue IR and mRNA levels are increased by antipsychotic drugs through their D2 receptor blocking actions (see Frey et al., 1986; Augood et al., 1991). These results indicated that the acute administration of D2 DA receptor antagonists increased NT levels in the striatum and nuc. accumbens, and that antipsychotic drugs (clozapine, fluperlapine) showing a relative lack of extrapyramidal side effects may be characterized by a failure to maintain increased NT levels in the basal ganglia upon long-term treatment in contrast to chronic haloperidol, chlorpromazine, and sulpiride (Frey et al., 1986). Instead, the D1 receptor antagonist 23390 acutely reduced the striatal NT tissue levels (Frey et al., 1986). The signs of increased NT storage and synthesis in the striatum - at least after long-term treatment with haloperidol - have been found to be associated with reduced NT IR efflux into the ECF in the ventral striatum (Gruber et al., 2002). The NT mRNA signals as studied with in situ hybridization are normally sparsely distributed (Schiffmann and Vanderhaeghen, 1993) and markedly increased by D2 antagonist treatment in the MSN representing the projection neurons (Augood et al., 1991). Thus, NT peptides may be synthesized and released from the D2 enriched striato-pallidal and D1 enriched striato-nigral GABA neurons to activate NTS1 receptors through extrasynaptic transmission. Antagonistic NTS1-D2 receptor-receptor interaction in 
putative NTS1-D2 heteromers have been repeatedly demonstrated in the striatum (Agnati et al., 1983a; Von Euler and Fuxe, 1987; von Euler, 1991; Li et al., 1994b; Diaz-Cabiale et al., 2002) located on the striatal DA terminals (NTS1-D2 autoreceptor interactions, Tanganelli et al. (1989)) and at the postjunctional level (Fuxe et al., 1992, 1995; Tanganelli et al., 1994; Li et al., 1995a) as indicated from microdialysis studies. A major achievement by Ferraro et al. $(1995,2011,2012)$ has also been the discovery that NT peptides - via facilitatory NTS1-NMDA receptor-receptor interactions - can enhance the synaptic glutamate transmission. In this way, extrasynaptic and synaptic signals can become integrated as previously shown by Liu and colleagues through demonstration of D5-GABAA, D1-NMDA, and D2-NMDA heteromer formation and their receptor-receptor interactions (Liu et al., 2000; Lee et al., 2002, 2005). Specifically, the NT peptides when released can enhance the glutamate synaptic signaling onto the striato-pallidal GABA neurons through the enhancing NTS1-NMDA receptorreceptor interaction (Tanganelli et al., 2012). This increased activation of the striato-pallidal GBA neurons is further strengthened by the antagonistic D2-NTS1 receptor-receptor interactions at the postjunctional level of the DA transmission reducing D2 signaling and its inhibitory action on the striato-pallidal GABA neurons (Tanganelli et al., 2012). The antagonistic NTS1-D2 autoreceptor interaction at the DA terminal level in contrast will increase DA release which via diffusion can increase D1 receptor signaling in the direct pathway since antagonistic D1-NTS1 receptor-receptor interactions do not exist. The net result of the NT extrasynaptic signaling will therefore be an increase in the activity of the striato-pallidal GABA neurons. This leads to increased motor inhibition balanced by increased activity of the direct pathway mediating motor initiation via increasing D1 receptor activity in the striato-entopeduncular-nigral GABA pathway.

It seems that cholecystokinin (CCK) peptides from glutamate synapses and NT peptides from MSN have similar functional and neurochemical actions by reducing and signaling of the $\mathrm{D} 2$ protomers in putative CCK2-D2 and NTS1-D2 heteromers, respectively but with the difference that NTS1 may also form heteromers with NMDA receptors. In line with these observations, threshold doses of CCK and NT peptides have been found to produce synergistic effects on D2 receptor affinity and DA release as seen in microdialysis studies (Tanganelli et al., 1993).

\section{Afferents \\ Cortico-striatal and thalamo-striatal glutamate synapses.} These glutamate synapses have a major impact on the firing of the striatal projection neurons and the striatal interneurons (Bennett and Bolam, 1994; Surmeier et al., 2007; Tepper et al., 2007; Gerfen and Surmeier, 2011). It is of interest that CCK immunoreactivity exists in the cortico-striatal glutamate neurons (Morino et al., 1994). CCK peptides may therefore be released from these glutamate synapses via spillover or extrasynaptic release to modulate the activity of the striatal local circuits via extrasynaptic transmission. In view of the demonstration of antagonistic CCK2-D2 receptorreceptor interactions in putative CCK2-D2 heteromers (Fuxe et al., 1981, 1983; Agnati et al., 1983b; Li et al., 1995b; Dasgupta et al., 1996) in the striato-pallidal GABA neurons (postjunctional CCK2 receptors) and on the striatal DA afferents (Tanganelli et al., 1990,
2001) one role of the CCK peptides released upon firing of the cortico-striatal neurons may be to enhance glutamate signaling on the D1 enriched direct pathway versus the D2 enriched striatopallidal GABA pathways eliciting motor inhibition. The existence of striatal nerve cells coexpressing CCK2 and D2 receptor mRNAs have in fact been demonstrated (Hansson et al., 1998). Thus, CCK2 activation by the diffusing CCK peptides in the local circuit will increase DA release by inhibiting the signaling over the D2 autoreceptor and the postjunctional D2 but not D1 signaling will be reduced. This will result in increased D1 signaling in the D1 enriched direct pathway favoring motor initiation.

It is of substantial interest that DA D1 receptors are involved in the modulation of DA D2 receptors induced by CCK receptor subtypes in rat neostriatal membranes (Li et al., 1994a), in view of the recent demonstration of DA D1-D2 heteromers by George and O'Dowd (2007) operating via a calcium signaling pathway. They have now been shown to exist in DA D1 expressing neurons especially in nuc accumbens (20-30\%) and in the globus pallidus (59\%; Hasbi et al., 2011). Our findings in 1994 (Li et al., 1994a), which demanded the coexistence of D1 and D2 receptors in the same striatal neurons, indicated that CCK-8 can reduce or increase the affinity of DA D2 receptors in rat neostriatal membrane preparations depending on the activity at the $\mathrm{D} 1$ receptors which when activated caused the CCK- 8 to increase the affinity of the D2 receptors instead of reducing it. Thus, D1 receptors exert a switching role in the modulation of D2 receptors by CCK receptors. Our hypothesis is that the molecular basis for this phenomenon is the existence of CCK2-D1-D2 trimeric heteromers or trimeric receptor mosaics in which the allosteric receptor-receptor interaction between CCK2-D2 receptors becomes markedly altered through the activation of the D1 receptor. In view of the fact that CCK2 receptor activation does not alter the binding characteristics of the D1 receptors it may be that the receptor mosaic has a triangular geometry.

It should be noticed that antipsychotic drugs, after subchronic treatment, increase the CCK octapeptide tissue levels in striatum and the meso-limbic system and remain increased even 4 weeks after cessation of treatment (Frey, 1983). Thus, the blockade of the $\mathrm{D} 2$ receptors results in a sustained increase in the expression of CCK peptides which if leading to increased release may reduce the affinity of the D2 receptors which may assist in the maintenance of antipsychotic actions (see Fuxe et al., 2009).

DA, 5-HT and histamine afferents. The highly dense DA nerve terminal plexa in the dorsal striatal cellular network originate from the substantia nigra in the ventral midbrain (see Anden et al., 1964; Fuxe et al., 1970b,c, 2007a), the moderately dense 5-HT nerve terminal plexa from the midbrain raphe (Anden et al., 1965, 1966; see Fuxe et al., 1970b,c, 2007a) and the histamine nerve terminal plexa from the tubero-mammillary nucleus in the hypothalamus (Haas and Panula, 2003). These three terminal networks originating from the brainstem mainly operate via extrasynaptic transmission to modulate the dorsal striatal cellular networks using various subtypes of dopamine (D1-D5), 5-HT (Di Matteo et al., 2008) and histamine (mainly $\mathrm{H} 2-\mathrm{H} 3$ ) receptors with extrasynaptic receptors in dominance, see special issue on the basal ganglia (Fuxe et al., 2008a). These receptors are located both on projection 
neurons and interneurons as well as on the afferent nerve terminal networks. The DA and 5-HT signals can in part become integrated via the existence of D2-5-HT2A heteromers (BorrotoEscuela et al., 2010; Lukasiewicz et al., 2010; Albizu et al., 2011) mainly located in the striato-pallidal GABA neurons. We found that the 5-HT2AR-mediated phospholipase C (PLC) activation was synergistically enhanced by the concomitant activation of the D2LR and costimulation of D2LR and 5-HT2AR within the heteromer led to inhibition of the D2LR functioning, thus suggesting the existence of a 5-HT2AR-mediated D2LR trans-inhibition phenomenon (Borroto-Escuela et al., 2010). Furthermore, 5-HT2AR expression is required to obtain the complete blockade of the D2R antagonist haloperidol on the MK-801-induced increase in locomotion (Albizu et al., 2011).

The DA and histamine signals can instead become integrated by the existence of DA D1-histamine $\mathrm{H} 3$ receptor heteromers giving a selective link to MAPK signaling in the striato-entopeduncularnigral GABA neurons forming the direct striatal pathway (Moreno et al., 2010).

Through these different types of brainstem afferents, the sensory-motor regulation of the dorsal striatum can obtain information from a motor system favoring movements (the nigral DA system), from an emotional system favoring an elevation of mood (midbrain raphe 5-HT system), and from a sleepwakefulness system favoring arousal (the tubero-mammillary histamine system).

\section{Interneurons}

Cholinergic interneurons. The large aspiny cholinergic interneurons represent $1-3 \%$ if the striatal neurons and give rise to highly dense nerve terminal plexus all over the cellular networks of the striatum and possess a slow firing tonic in nature (for recent reviews see Pisani et al., 2007; Oldenburg and Ding, 2011). This plexus mainly operates via extrasynaptic transmission (Descarries and Mechawar, 2000) and modulates the transmission of the medium spiny GABA projection neurons, the different types of striatal interneurons and the striatal afferents mainly via five subtypes of muscarinic receptors (M1-M5) but also via nicotinic receptors (Figure 1). The striatal M1 receptors are mainly present in the two major projection neurons, the D2 enriched striato-pallidal GABA neurons and the D1 enriched striato-entopeduncular-nigral GABA neurons (direct pathway). It is mainly coupled to $\mathrm{Gq} / 11$ and signal by increasing intracellular Ca levels and PLC and protein kinase C (PKC) activities. In contrast, M4 is predominantly expressed in the direct pathway and coupled to Gi/o reducing calcium channel activity and activity in the AC-PKA-CREB intracellular pathway. M1 excites the MSN and enhance their spiking by modulating potassium and Cav channels and M4 differentially shapes these actions in the striato-nigral GABA pathways by inhibiting the Cav channels (see Oldenburg and Ding, 2011). In addition, M2 and M3 receptor activation on glutamate synapses modulates the glutamate release in an inhibitory way also reducing the M1 induced excitatory effects on MSN. M4 receptors together with M2 receptor, which is linked to Gi/o as well, are also located on the cholinergic interneurons where they function as inhibitory autoreceptors.
The role of endocannabinoids. It is of substantial interest that another type of extrasynaptic transmission mediated by endocannabinoids is involved in mediating the actions of M1 mediated transmission of the cholinergic interneurons. Thus, long-term synaptic depression in MSN is modulated by cholinergic interneurons (Wang et al., 2006). M1 mediated actions at dendritic spines of MSN leads to reduced activity of Cav1.3 channels which brings down the formation and subsequent migration of endocannabinoids potentially located in microvesicles (Agnati et al., 2010a) with reduced activation inter alia of the extrasynaptic CB1 receptors on the glutamate terminals. In this way the synaptic glutamate excitatory transmission is increased. However, DA extrasynaptic transmission via D2 mediated inhibitory control of the cholinergic interneurons will restore the activation of the retrograde endocannabinoid signaling and LTD. The mGluR1/5 mediated extrasynaptic transmission of glutamate also plays an important role for LTD development since this receptor - through Gq/11 coupling leading to increased IP3 levels - will increase intracellular Ca levels followed by activation of PLC and DAG lipase, and increased formation of endocannabinoids and reduction of excitatory glutamate transmission.

The complexity of the M1 mediated cholinergic actions on formation of endocannabinoids, however, should be noticed since at inhibitory GABA synapses located on the shafts of MSN the M1 receptor activation leads to an increase in formation of endocannabinoid 2-arachidonoylglycerol (2-AG) with increased CB1 receptor activity at the GABA synapses and suppression of synaptic GABA transmission (Narushima et al., 2007). The reason is likely that in these microdomains the M1 excitatory coupling to PLC and DAG lipase dominates and here also M1 likely acts synergistically with mGluR1/5 to enhance 2-AG formation and thus the retrograde inhibitory signaling on the GABA synapses (see Uchigashima et al., 2007). It should be underlined that CB1 receptors also exist in the striato-pallidal GABA neurons and in the striatoentopeduncular-nigral GABA neurons (Martin et al., 2008) and endocannabinoids can therefore exert direct actions on these neurons reducing inter alia D2 signaling in the striato-pallidal GABA neurons through participation in CB1-D2 heteromers and CB1D2-A2A trimers (Fuxe et al., 2008b; Marcellino et al., 2008). This may be part of an inhibitory feedback since D2 receptor activation leads to an increased formation of anandamide (see Piomelli, 2003).

Recently muscarinic acetylcholine receptor homo- and heterodimerization has been observed in live cells (Goin and Nathanson, 2006). The existence of high affinity M1-M2, M2-M3, and M1M3 mAChR heterodimers could be demonstrated and an increased agonist induced downregulation of M3 developed when present as a protomer in M2-M3 heteromers. Based on these findings it will be of interest if in fact M2-M3 heteromers exist in the striatal glutamate terminals where they are collocated. We are presently studying to which extent striatal DA and cholinergic transmission can become integrated through the formation of different types of heteromers of DA and muscarinic receptors, especially D1-M4 (Figure 1), D2-M1, and D2-M4 heteromers. Such discoveries would open up new possibilities for treatment of Parkinson disease and improve the use of muscarinic receptor antagonists in the treatment of this disease based on an increased activity of 


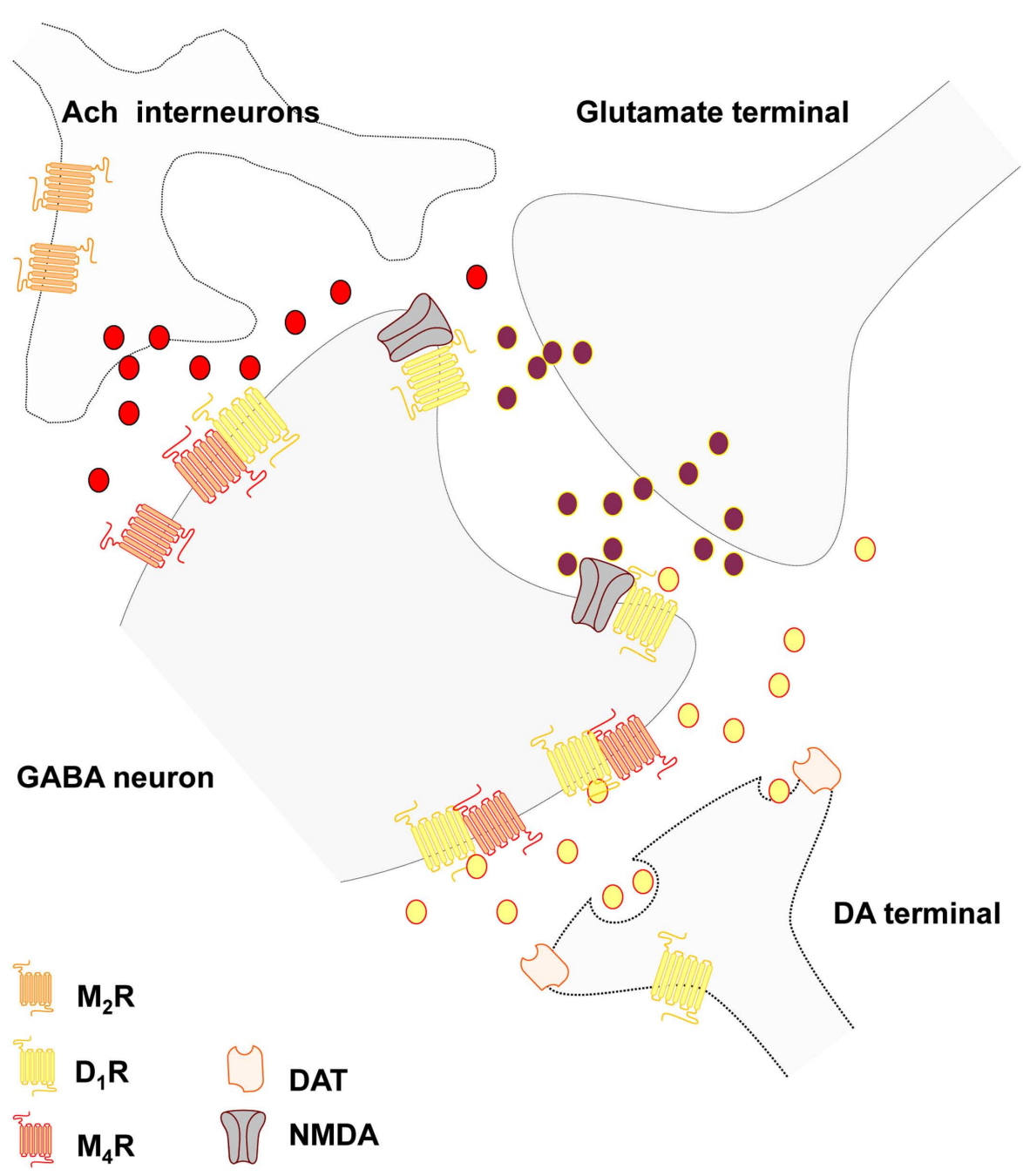

FIGURE 1 | Schematic representation of the postulated D1-M4 receptor heteromers in the local striatal circuits of the striato-entopenduncularnigral GABA neurons. The $D_{1}-M_{4}$ receptor heteromers probably mainly exist in an extrasynaptic location on the dendritic spines and on the dendritic shafts of these neurons where inputs from striatal dopamine and cholinergic transmission can become integrated through the formation of this heteromers. The $\mathrm{D}_{1}$-NMDA receptor mosaics in the glutamate synapses are also indicated. Thus, dopamine may diffuse into glutamate synapse to modulate NMDA signaling unless $D_{1}$ exclusively binds to extrajunctional NMDA receptors. the cholinergic neurons related to a reduced activation of the D2 receptors located on these neurons (Pisani et al., 2007). It has been proposed that the adaptive changes taking place in PD involves an increase in the formation of RGS4, a regulator of G protein signaling which reduces the coupling of the M4 autoreceptor to the Cav2 calcium channels and to the potassium cannels leading to overactivity of these interneurons (Ding et al., 2006; Pisani et al., 2007). A new hypothesis may be that the disruption of the M4 autoreceptor function may be caused by dysfunction of a D2-M4 heteromer located on the striatal interneurons due to the abnormal reduction of D2 signaling in the D2 protomer in Parkinson disease.

The reason that anticholinergic drugs like scopolamine can block catalepsy induced by both D2 and D1 receptor antagonists was in 1988 explained within the frame of the hypothesis of different striatal efferent pathways one being D2 enriched and the other D1 enriched (Ogren and Fuxe, 1988). The mechanism may be the preferential enrichment of inhibitory M4 receptors in the striato-entopeduncular-nigral GABA neurons vs. the striato-pallidal GABA neurons both of which are enriched in excitatory $\mathrm{M} 1$ receptors (see above). The results from the overall pharmacological analysis of the catalepsy obtained, including the use of benzodiazepine antagonists (Ogren and Fuxe, 1988), could be explained on the basis of a circuitry involving D2 regulated striatopallidal GABA pathways and a D1 regulated circuitry involving D1 regulated nigro-thalamic GABA pathways. DA release and diffusion in the zona reticulata of the substantia nigra may take place from dendrites of nigral DA nerve cells via extrasynaptic transmission reaching inter alia D1 receptors on the striato-nigral GABA terminals enhancing the release of GABA with increased inhibition of the nigro-thalamic GABA pathway setting free the excitatory thalamo-cortical system from the motor thalamus (Ogren and Fuxe, 1988). 
GABA interneurons. The calcium binding protein parvalbumin positive aspiny GABAergic interneurons exist mainly in two classes: the fast spiking interneurons and the low threshold spike (LTS) interneurons (Kawaguchi, 1995; Tepper et al., 2008). They are driven by cortico-striatal glutamate synapses and project to the MSN and mediate powerful feed-forward inhibition of the MSN via GABAergic synapses. These are striatal interneurons where synaptic high speed GABA transmission dominates and can profoundly bring down spiking in the MSN and controlling its timing.

Other striatal GABAergic interneurons instead coexpress also somatostatin, neuropeptide Y (NPY), and neuronal nitric oxide synthase (NOS) and likely operate via both synaptic (GABA) and VT (somatostatin, NPY, and NOS; see Figure 2).

They are evenly dispersed all over the striatum with widespread collaterals and are neurophysiologically characterized as LTS neurons with persistent depolarization (Kawaguchi, 1995). They receive cortical glutamate inputs and likely mediate feedforward modulation of the striatal networks. Somatostatin and NPY peptides may modulate the activity of the neuronal and glial cell populations via extrasynaptic and long distance VT through their striatal receptor subtypes (Figure 2). Rocheville et al. (2000) have also demonstrated that somatostatin receptor 5 (SSTR5) can form heteromers with D2 receptors which are formed after agonist activation (Rocheville et al., 2000). Thus, again receptor-receptor interaction in heteromers can play a role in the integration of signals in the neuronal and glial networks of the brain (Agnati et al., 2010b; Fuxe et al., 2010a,b). Heteromers between NPY Y1 and alpha2 receptors have also been indicated (Fuxe et al., 2008c).

Also nitric oxide (NO) is formed in these NOS positive cells and diffuse into adjacent nerve, glial, and endothelial cells via VT (Fuxe et al., 2010a; Figure 2). Most of them likely express soluble guanylate cyclase which indicates that they are likely targets for NO produced by the NOS positive GABA interneurons (see Kawaguchi, 1995). This communication upon activation by glutamate synapses of these neurons modulates transmitter release and increases blood flow according to the pattern of cortico-striatal glutamate projection activation of these neurons. This is likely linked to the activation of discrete populations of striatal projection neurons. In this way the assemblies of activated glutamate projection neurons can perform their tasks in cellular networks that adapt to this task to achieve an optimal sensory-motor function.

Adenosine as a VT signal in the striatal cellular networks.

Adenosine is an endogenous nucleoside mostly formed as a degradation product of adenosine triphosphate (ATP) and to a lesser degree from S-adenosyl-L-homocysteine (SAH) metabolism and present in all cells of the striatal cellular networks and in the ECS (Ferre and Fuxe, 2000; Ciruela et al., 2011). Upon adenosine generation in neuronal and glial cells, it can be intracellularly phosphorylated to form AMP, react with L-homocysteine to form $\mathrm{SAH}$ or be eliminated out of the cells by means of ubiquitous

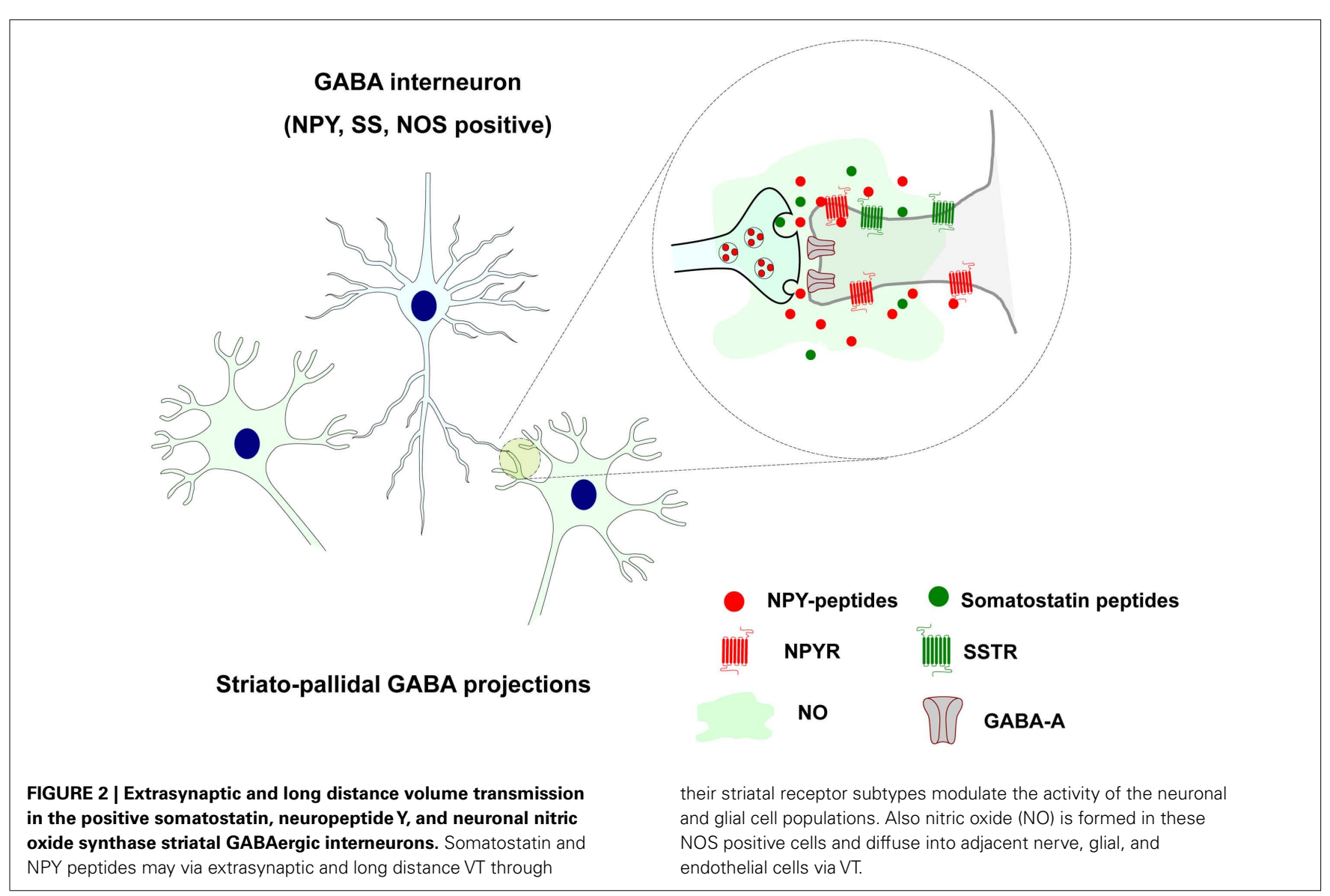


nitrobenzylthioinosine-sensitive equilibrative nucleoside transporters (ENTs; Cunha, 2005). In the cellular networks, extracellular adenosine can also derive from ATP released from nerve and glial cells including release from glutamate terminals together with glutamate. Intra- and extra-cellular adenosine can be deaminated to form inosine by the action of intra and ecto-adenosine deaminase, respectively. In the nervous system the extracellular concentration of adenosine raises as a function of the neuronal activity, it acts as an energy-dependent neuromodulator through combined presynaptic and postsynaptic actions through VT (Figure 3; Ferre and Fuxe, 2000; Sebastiao and Ribeiro, 2000; Fredholm et al., 2005; Ciruela et al., 2011). Therefore, extracellular adenosine regulates several functions in the brain, including neuronal viability, neuronal membrane potential, propagation of action potentials, astrocytic functions, microglia reactivity, primary metabolism in both neurons and astrocytes, and blood flow (Ferre and Fuxe, 2000; Fredholm et al., 2005; Ciruela et al., 2011).
The most abundant and homogeneously distributed adenosine receptor in the brain is the extrasynaptic inhibitory A1R, which is functionally coupled to members of the pertussis toxin-sensitive family of $\mathrm{G}$ proteins $(\mathrm{Gi} / \mathrm{o})$ and whose activation regulates the activity of membrane and intracellular proteins such as adenylate cyclase, $\mathrm{Ca} 2+$ channels, $\mathrm{K}+$ channels, and phospholipase $\mathrm{C}$. In contrast, the extrasynaptic A2AR is expressed at high levels in only a few regions of the brain, namely the dorsal striatum, the olfactory tubercle, and the nucleus accumbens. The A2AR is mostly coupled to Gs in the peripheral systems but mediates its effects predominantly through activation of Golf in the striatum (see Ciruela et al., 2011).

It is of substantial interest that adenosine receptor can form heteromers with extrasynaptic DA receptors and glutamate receptors to modulate striatal cellular networks (Fuxe et al., 1998; Ciruela et al., 2011). A1R has been found to heteromerize with the dopamine D1 receptor (D1R), this phenomenon being essential

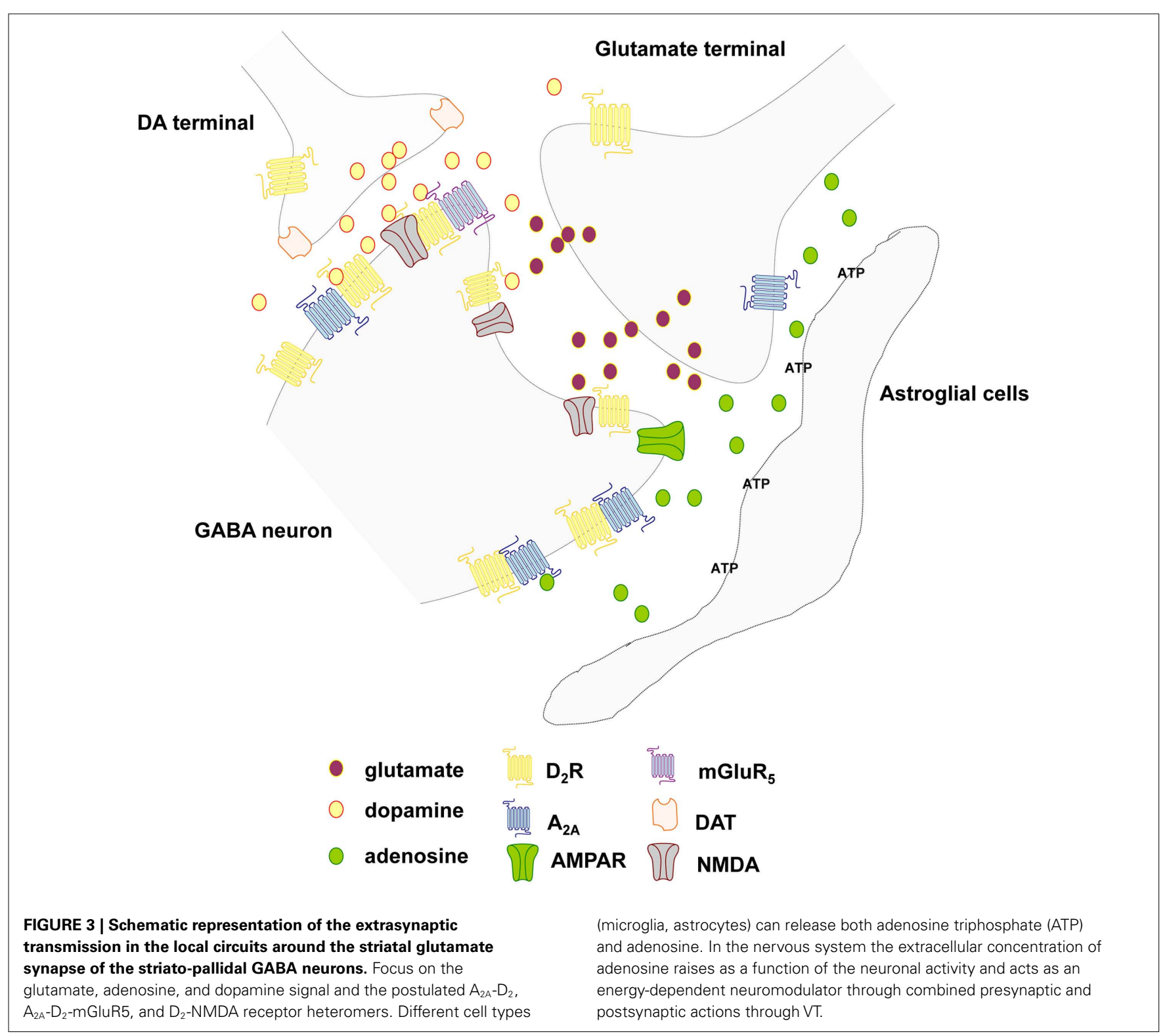


for differential desensitization mechanisms and for receptor trafficking (Torvinen et al., 2002). It also contributes to reduce EEG and behavioral arousal (Fuxe et al., 2007b). The heterodimer composed by the A1R and the metabotropic glutamate type $1 \alpha$ $(\mathrm{mGlu} 1 \alpha)$ receptor seems to play a key role in preventing glutamate excitotoxicity (Ciruela et al., 2001).

The A2AR possesses the ability to heteromerize with the DA D2 receptor (D2R; Figure 3; Hillion et al., 2002; Canals et al., 2003). The latter receptor-receptor interaction underlies the molecular mechanism behind the antagonistic adenosine-dopamine interactions that regulate the function of the GABAergic enkephalinergic striato-pallidal GABA neurons and reduces behavioral arousal (Fuxe et al., 2007b). Finally, the A2AR also heteromerizes with the metabotropic glutamate type 5 (mGlu5) receptor, and in this case, a synergistic functional interaction has been demonstrated at both biochemical and behavioral levels (Ferre et al., 2002). They also synergize to bring down D2 receptor function in A2A-D2mGluR5 receptor mosaics located in the perisynaptic regions of the glutamate synapses representing integrative heteromers for extracellular adenosine, dopamine and glutamate signals (Cabello et al., 2009; Ciruela et al., 2011) as early indicated in studies on receptorreceptor interactions (see Popoli et al., 2001; Fuxe et al., 2003). These extrasynaptic trimeric heteromers may represent centers for integration of VT signals. In the integration of the synaptic and extrasynaptic signals of the striatal networks the heteromeric complexes between GPCRs and ion-channel receptors in the synaptic regions play a special role inter alia D1-NMDA and D2-NMDA and D5-GABAA heteromers (Liu et al., 2000, 2006; Lee et al., 2002).

\section{REFERENCES}

Agnati, L. F., Bjelke, B., and Fuxe, K. (1992). Volume transmission in the brain. Am. Sci. 80, 362-373.

Agnati, L. F., Fuxe, K., Benfenati, F., and Battistini, N. (1983a). Neurotensin in vitro markedly reduces the affinity in subcortical limbic $3 \mathrm{H}$ $\mathrm{N}$-propylnorapomorphine binding sites. Acta Physiol. Scand. 119, 459-461.

Agnati, L. F., Fuxe, K., Benfenati, F., Celani, M. F., Battistini, N., Mutt, V., Cavicchioli, L., Galli, G., and Hokfelt, T. (1983b). Differential modulation by CCK- 8 and CCK- 4 of $[3 \mathrm{H}]$ spiperone binding sites linked to dopamine and 5hydroxytryptamine receptors in the brain of the rat. Neurosci. Lett. 35, 179-183.

Agnati, L. F., Fuxe, K., Nicholson, C., and Sykova, E. (2000). Volume Transmission Revisited, in Progress in Brain Research, Vol. 125 (Amsterdam: Elsevier), 1-447.

Agnati, L. F., Fuxe, K., Zoli, M., Ozini, I., Toffano, G., and Ferraguti, F. (1986). A correlation analysis of the regional distribution of central enkephalin and beta-endorphin immunoreactive terminals and of opiate receptors in adult and old male rats.

\section{CONCLUSIONS}

Evidence is accumulating that extrasynaptic and long distance VT plays a major role in communication within the neuronal-glial networks of the brain as exemplified here within the striatal cellular networks. The integration of synaptic with extrasynaptic and long distance VT signals may take place to a substantial degree via the formation of receptor heteromers between ion-channel receptors and GPCRs in the plasma membrane of synaptic regions. The integration among VT signals may to a substantial degree occur via GPCR heteromers including higher order heteromers in dendrites, axon terminals, and soma including extrasynaptic regions. This opens up a new way of understanding communication in the CNS.

\section{ACKNOWLEDGMENTS}

This work was supported by grants from the Swedish Research Council (04X-715), Hjärnfonden, Torsten, and Ragnar Söderberg, Telethon TV3's La Marató Foundation 2009 and M.M. Wallenberg Foundation to Kjell Fuxe, Karolinska Institutets Forskningsstiftelser 2010 and 2011 to Dasiel O. Borroto-Escuela, and also by grants SAF2008-01462 and Consolider-Ingenio CSD2008-00005 from Ministerio de Ciencia e Innovación and ICREA Academia2010 from the Catalan Institution for Research and Advanced Studies to Francisco Ciruela, and Telethon TV3's La Marató Foundation 2009 and grant SAF2008-04943-C02-02 to Pere Garriga. Alexander O. Tarakanov has not received any support for this work.

O., Miot, S., Gras, C., Gardier, A. M., Gallego, J., Hamon, M., Lanfumey, L., Gasnier, B., Giros, B., and El Mestikawy, S. (2010). VGLUT3 (vesicular glutamate transporter type 3 ) contribution to the regulation of serotonergic transmission and anxiety. J. Neurosci. 30, 2198-2210.

Anden, N. E., Carlsson, A., Dahlstroem, A., Fuxe, K., Hillarp, N. A., and Larsson, K. (1964). Demonstration and mapping out of nigroneostriatal dopamine neurons. Life Sci. 3, 523-530.

Anden, N. E., Dahlstrom, A., Fuxe, K., and Larsson, K. (1965). Mapping out of catecholamine and 5-hydroxytryptamine neurons innervating the telencephalon and diencephalon. Life Sci. 4, 1275-1279.

Anden, N. E., Fuxe, K., and Larsson, K. (1966). Effect of large mesencephalic-diencephalic lesions on the noradrenalin, dopamine and 5-hydroxytryptamine neurons of the central nervous system. Experientia 22, 842-843.

Andersson, K., Fuxe, K., Eneroth, P., Nyberg, F., and Roos, P. (1981). Rat prolactin and hypothalamic catecholamine nerve terminal systems. Evidence for rapid and discrete increases in dopamine and noradrenaline turnover in the hypophysectomized male rat. Eur. J. Pharmacol. 76, 261-265.

Aoki, C. (1992). Beta-adrenergic receptors: astrocytic localization in the adult visual cortex and their relation to catecholamine axon terminals as revealed by electron microscopic immunocytochemistry. J. Neurosci. 12, 781-792.

Aoki, C., and Pickel, V. M. (1992). C-terminal tail of beta-adrenergic receptors: immunocytochemical localization within astrocytes and their relation to catecholaminergic neurons in N. tractus solitarii and area postrema. Brain Res. 571, 35-49.

Aoki, C., Venkatesan, C., Go, C. G., Forman, R., and Kurose, H. (1998). Cellular and subcellular sites for noradrenergic action in the monkey dorsolateral prefrontal cortex as revealed by the immunocytochemical localization of noradrenergic receptors and axons. Cereb. Cortex 8 , 269-277.

Functional crosstalk and het ization of serotonin 5-HT2A and dopamine D2 receptors. Neuropharmacology 61, 770-777.

Amilhon, B., Lepicard, E., Renoir, T., Mongeau, R., Popa, D., Poirel,
Arvidsson, U., Riedl, M., Chakrabarti, S., Lee, J. H., Nakano, A. H., Dado, R. J., Loh, H. H., Law, P. Y., (1995). Distribution and targeting Wessendorf, M. W., and Elde, R. 
of a mu-opioid receptor (MOR1) in brain and spinal cord. J. Neurosci. 15, 3328-3341.

Augood, S. J., Kiyama, H., Faull, R. L., and Emson, P. C. (1991). Differential effects of acute dopaminergic $\mathrm{D} 1$ and $\mathrm{D} 2$ receptor antagonists on proneurotensin mRNA expression in rat striatum. Brain Res. Mol. Brain Res. 9, 341-346.

Bennett, B. D., and Bolam, J. P. (1994). Synaptic input and output of parvalbumin-immunoreactive neurons in the neostriatum of the rat. Neuroscience 62, 707-719.

Bennett, M. V., Contreras, J. E., Bukauskas, F. F., and Saez, J. C. (2003). New roles for astrocytes: gap junction hemichannels have something to communicate. Trends $\mathrm{Neu}$ rosci. 26, 610-617.

Bjelke, B., and Fuxe, K. (1993). Intraventricular beta-endorphin accumulates in DARPP-32 immunoreactive tanycytes. Neuroreport 5, 265-268.

Bolam, J. P., Somogyi, P., Takagi, H., Fodor, I., and Smith, A. D. (1983). Localization of substance Plike immunoreactivity in neurons and nerve terminals in the neostriatum of the rat: a correlated light and electron microscopic study. $J$. Neurocytol. 12, 325-344.

Borroto-Escuela, D. O., RomeroFernandez, W., Tarakanov, A. O., Marcellino, D., Ciruela, F., Agnati, L. F., and Fuxe, K. (2010). Dopamine D2 and 5-hydroxytryptamine 5-HT(A) receptors assemble into functionally interacting heteromers. Biochem. Biophys. Res. Commun. 401, 605-610.

Borroto-Escuela, D. O., Tarakanov, A. O., Guidolin, D., Ciruela, F., Agnati, L. F., and Fuxe, K. (2011). Moonlighting characteristics of $\mathrm{G}$ proteincoupled receptors: focus on receptor heteromers and relevance for neurodegeneration. IUBMB Life 63, 463-472.

Cabello, N., Gandia, J., Bertarelli, D. C., Watanabe, M., Lluis, C., Franco, R., Ferre, S., Lujan, R., and Ciruela, F. (2009). Metabotropic glutamate type 5, dopamine D2 and adenosine A2a receptors form higherorder oligomers in living cells. J. Neurochem. 109, 1497-1507.

Caille, I., Dumartin, B., and Bloch, B. (1996). Ultrastructural localization of D1 dopamine receptor immunoreactivity in rat striatonigral neurons and its relation with dopaminergic innervation. Brain Res. 730, 17-31.

Canals, M., Marcellino, D., Fanelli, F., Ciruela, F., De Benedetti, P., Goldberg, S. R., Neve, K., Fuxe, K., Agnati,
L. F., Woods, A. S., Ferre, S., Lluis, C., Bouvier, M., and Franco, R. (2003). Adenosine A2A-dopamine D2 receptor-receptor heteromerization: qualitative and quantitative assessment by fluorescence and bioluminescence energy transfer. J. Biol. Chem. 278, 46741-46749.

Carmignoto, G. (2000). Reciprocal communication systems between astrocytes and neurones. Prog. $\mathrm{Neu}$ robiol. 62, 561-581.

Cercos, M. G., De-Miguel, F. F., and Trueta, C. (2009). Real-time measurements of synaptic autoinhibition produced by serotonin release in cultured leech neurons. J. Neurophysiol. 102, 1075-1085.

Chen, K. C., Hoistad, M., Kehr, J., Fuxe, K., and Nicholson, C. (2002a). Quantitative dual-probe microdialysis: mathematical model and analysis. J. Neurochem. 81, 94-107.

Chen, K. C., Hoistad, M., Kehr, J., Fuxe, K., and Nicholson, C. (2002b). Theory relating in vitro and in vivo microdialysis with one or two probes. J. Neurochem. 81, 108-121.

Ciruela, F., Escriche, M., Burgueno, J., Angulo, E., Casado, V., Soloviev, M. M., Canela, E. I., Mallol, J., Chan, W. Y., Lluis, C., Mcilhinney, R. A., and Franco, R. (2001). Metabotropic glutamate lalpha and adenosine $\mathrm{Al}$ receptors assemble into functionally interacting complexes. J. Biol. Chem. 276, 18345-18351.

Ciruela, F., Gomez-Soler, M., Guidolin, D., Borroto-Escuela, D. O., Agnati, L. F., Fuxe, K., and FernandezDuenas, V. (2011). Adenosine receptor containing oligomers: their role in the control of dopamine and glutamate neurotransmission in the brain. Biochim. Biophys. Acta 1808, 1245-1255.

Cunha, R. A. (2005). Neuroprotection by adenosine in the brain: from $\mathrm{A}(1)$ receptor activation to $\mathrm{A}(2 \mathrm{~A})$ receptor blockade. Purinergic Signal. 1, 111-134.

Dana, C., Vial, M., Leonard, K., Beauregard, A., Kitabgi, P., Vincent, J. P., Rostene, W., and Beaudet, A. (1989). Electron microscopic localization of neurotensin binding sites in the midbrain tegmentum of the rat. I. Ventral tegmental area and the interfascicular nucleus. J. Neurosci. 9, 2247-2257.

Dasgupta, S., Li, X. M., Jansson, A., Finnman, U. B., Matsui, T., Rinken, A., Arenas, E., Agnati, L. F., and Fuxe, K. (1996). Regulation of dopamine D2 receptor affinity by cholecystokinin octapeptide in fibroblast cells cotransfected with human CCKB and D2L receptor
cDNAs. Brain Res. Mol. Brain Res. 36, 292-299.

Del Arco, A., Segovia, G., Fuxe, K., and Mora, F. (2003). Changes in dialysate concentrations of glutamate and GABA in the brain: an index of volume transmission mediated actions? J. Neurochem. 85, 23-33.

De-Miguel, F. F., and Trueta, C. (2005). Synaptic and extrasynaptic secretion of serotonin. Cell. Mol. Neurobiol. 25 , 297-312.

Descarries, L., Beaudet, A., and Watkins, K. C. (1975). Serotonin nerve terminals in adult rat neocortex. Brain Res. 100, 563-588.

Descarries, L., Berube-Carriere, N. Riad, M., Bo, G. D., Mendez, J. A., and Trudeau, L. E. (2008). Glutamate in dopamine neurons: synaptic versus diffuse transmission. Brain Res. Rev. 58, 290-302.

Descarries, L., Gisiger, V., and Steriade, M. (1997). Diffuse transmission by acetylcholine in the CNS. Prog. Neurobiol. 53, 603-625.

Descarries, L., and Mechawar, N. (2000). Ultrastructural evidence for diffuse transmission by monoamine and acetylcholine neurons of the central nervous system. Prog. Brain Res. 125 27-47.

Descarries, L., Seguela, P., and Watkins, K. C. (1991). "Nonjunctional relationship of monoamine axon terminals in the cerebral cortex of adult rat," in Volume Transmission in the Brain, Novel Mechanisms for Neural Transmission, eds K. Fuxe and L. F. Agnati (New York: Raven Press), 53-62.

Descarries, L., Watkins, K. C., Garcia, S., Bosler, O., and Doucet, G. (1996). Dual character, asynaptic and synaptic, of the dopamine innervation in adult rat neostriatum: a quantitative autoradiographic and immunocytochemical analysis. J. Comp. Neurol. 375, 167-186.

Dewey, S. L., Smith, G. S., Logan, J., Brodie, J. D., Fowler, J. S., and Wolf, A. P. (1993). Striatal binding of the PET ligand 11C-raclopride is altered by drugs that modify synaptic dopamine levels. Synapse 13, 350-356.

Di Matteo, V., Di Giovanni, G., Pierucci, M., and Esposito, E. (2008). Serotonin control of central dopaminergic function: focus on in vivo microdialysis studies. Prog. Brain Res. 172, 7-44.

Diaz-Cabiale, Z., Fuxe, K., Narvaez, J. A., Finetti, S., Antonelli, T., Tanganelli, S., and Ferraro, L. (2002). Neurotensin-induced modulation of dopamine D2 receptors and their function in rat striatum: counteraction by a NTR1-like receptor antagonist. Neuroreport 13 , 763-766.

Ding, J., Guzman, J. N., Tkatch, T., Chen, S., Goldberg, J. A., Ebert, P. J., Levitt, P., Wilson, C. J., Hamm, H. E., and Surmeier, D. J. (2006). RGS4-dependent attenuation of M4 autoreceptor function in striatal cholinergic interneurons following dopamine depletion. Nat. Neurosci. 9, 832-842.

Duan, L., Yuan, H., Su, C. J., Liu, Y. Y., and Rao, Z. R. (2004). Ultrastructure of junction areas between neurons and astrocytes in rat supraoptic nuclei. World J. Gastroenterol. 10, 117-121.

Eghbali, M., Santoro, C., Paredes, W. Gardner, E. L., and Zukin, R. S. (1987). Visualization of multiple opioid-receptor types in rat striatum after specific mesencephalic lesions. Proc. Natl. Acad. Sci. U.S.A. 84, 6582-6586.

El Mestikawy, S., Wallen-Mackenzie, A., Fortin, G. M., Descarries, L., and Trudeau, L. E. (2011). From glutamate co-release to vesicular synergy: vesicular glutamate transporters. Nat. Rev. Neurosci. 12, 204-216.

Elde, R., Arvidsson, U., Riedl, M., Vulchanova, L., Lee, J. H., Dado, R., Nakano, A., Chakrabarti, S., Zhang, X., Loh, H. H., Law, P. Y., Hökfelt, T., and Wessendorf, M. (1995). Distribution of neuropeptide receptors. New views of peptidergic neurotransmission made possible by antibodies to opioid receptors. Ann. N. Y. Acad. Sci. 757, 390-404.

Falck, B., Hillarp, N. A., Thieme, G. and Torp, A. (1962). Fluorescence of catechol amines and related compounds condensed with formaldehyde. In J. Histochem. Cytochem. 10, 348-354.

Ferraro, L., Antonelli, T., O’Connor, W. T., Tanganelli, S., Rambert, F. A., and Fuxe, K. (1998). The effects of modafinil on striatal, pallidal and nigral GABA and glutamate release in the conscious rat: evidence for a preferential inhibition of striatopallidal GABA transmission. $\mathrm{Neu}$ rosci. Lett. 253, 135-138.

Ferraro, L., Beggiato, S., Tomasini, M. C., Fuxe, K., Tanganelli, S., and Antonelli, T. (2011). Neurotensin regulates cortical glutamate transmission by modulating $\mathrm{N}$ methyl-D-aspartate receptor functional activity: an in vivo microdialysis study. J. Neurosci. Res. 89, 1618-1626. 
Ferraro, L., O'Connor, W. T., Beggiato, S., Tomasini, M. C., Fuxe, K., Tanganelli, S., and Antonelli, T. (2012). Striatal NTS(1), dopamine $\mathrm{D}(2)$ and NMDA receptor regulation of pallidal GABA and glutamate release a dual-probe microdialysis study in the intranigral 6-hydroxydopamine unilaterally lesioned rat. Eur. J. Neurosci. 35, 207-220.

Ferraro, L., Tanganelli, S., O'Connor, W. T., Bianchi, C., Ungerstedt, U., and Fuxe, K. (1995). Neurotensin increases endogenous glutamate release in the neostriatum of the awake rat. Synapse 20, 362-364.

Ferre, S., and Fuxe, K. (2000). Adenosine as a volume transmission signal. A feedback detector of neuronal activation. Prog. Brain Res. 125, 353-361.

Ferre, S., Karcz-Kubicha, M., Hope, B. T., Popoli, P., Burgueno, J., Gutierrez, M. A., Casado, V., Fuxe, K., Goldberg, S. R., Lluis, C., Franco, R., and Ciruela, F. (2002). Synergistic interaction between adenosine $\mathrm{A} 2 \mathrm{~A}$ and glutamate mGlu5 receptors: implications for striatal neuronal function. Proc. Natl. Acad. Sci. U.S.A. 99, 11940-11945.

Fredholm, B. B., Chen, J. F., Cunha, R. A., Svenningsson, P., and Vaugeois, J. M. (2005). Adenosine and brain function. Int. Rev. Neurobiol. 63, 191-270.

Frey, P. (1983). Cholecystokinin octapeptide levels in rat brain are changed after subchronic neuroleptic treatment. Eur. J. Pharmacol. 95, 87-92.

Frey, P., Fuxe, K., Eneroth, P., and Agnati, L. F. (1986). Effects of acute and long-term treatment with neuroleptics on regional telencephalic neurotensin levels in the male rat. $\mathrm{Neu}$ rochem. Int. 8, 429-434.

Froes, M. M., Correia, A. H., GarciaAbreu, J., Spray, D. C., Campos De Carvalho, A. C., and Neto, M. V. (1999). Gap-junctional coupling between neurons and astrocytes in primary central nervous system cultures. Proc. Natl. Acad. Sci. U.S.A. 96, 7541-7546.

Fuxe, K. (1963). Cellular localization of monoamines in the median eminence and in the infundibular stem of some mammals. Acta Physiol. Scand. 58, 383-384.

Fuxe, K. (1964). Cellular localization of monoamines in the median eminence and the infundibular stem of some mammals. Z. Zellforsch. Mikrosk. Anat. 61, 710-724.

Fuxe, K. (1965). Evidence for the Existence of Monoamine Neurons in the Central Nervous System. Uppsala:
Almqvist and Wiksells Boktryckeri.

Fuxe, K. (1979). Dopamine receptor agonists in brain research and as therapeutic agents. Trends Neurosci. $2,1-4$.

Fuxe, K., and Agnati, L. F. (eds). (1991b). Volume Transmission in the Brain, Novel Mechanisms for Neural Transmission. New York: Raven Press.

Fuxe, K., and Agnati, L. F. (1991a). "Two principle modes of electrochemical communication in the brain: volume versus wiring transmission," in Volume Transmission in the Brain: Novel Mechanisms of Neuronal Transmission, eds K. Fuxe and L. F. Agnati (New York: Raven Press), 1-9.

Fuxe, K., Agnati, L. F., Benfenati, F., Celani, M., Zini, I., Zoli, M., and Mutt, V. (1983). Evidence for the existence of receptor-receptor interactions in the central nervous system. Studies on the regulation of monoamine receptors by neuropeptides. J. Neural Transm. Suppl. 18, 165-179.

Fuxe, K., Agnati, L. F., Benfenati, F., Cimmino, M., Algeri, S., Hokfelt, T., and Mutt, V. (1981). Modulation by cholecystokinins of $3 \mathrm{H}$-spiroperidol binding in rat striatum: evidence for increased affinity and reduction in the number of binding sites. Acta Physiol. Scand. 113, 567-569.

Fuxe, K., Hokfelt, T., Jonsson, G., and Ungerstedt, U. (1970b). "Fluorescence microscopy in neuroanatomy," in Contemporary Research Methods in Neuroanatomy, eds W. J. H. Narura and S. O. E. Ebbesson (Berlin: Springer-Verlag), 275-314.

Fuxe, K., Hokfelt, T., and Ungerstedt, U. (1970c). Morphological and functional aspects of central monoamine neurons. Int. Rev. Neurobiol. 13, 93-126.

Fuxe, K., Agnati, L. F., Cintra, A., Andersson, K., Eneroth, P., Harfstrand, A., Zoli, M., and Goldstein, M. (1988a). Studies on central D1 receptors role in volume transmission, neuroendrocrine regulation and release of noradrenaline. Adv. Exp. Med. Biol. 235, 83-119.

Fuxe, K., Cintra, A., Agnati, L. F., Harfstrand, A., and Goldstein, M. (1988b). Studies on the relationship of tyrosine hydroxylase, dopamine and cyclic amp-regulated phosphoprotein-32 immunoreactive neuronal structures and $\mathrm{dl}$ receptor antagonist binding sites in various brain regions of the male rat-mismatches indicate a role of $\mathrm{d} 1$ receptors in volume transmission. Neurochem. Int. 13, 179-197.

Fuxe, K., Agnati, L. F., Zoli, M., Cintra, A., Härfstrand, A., von Euler,
G., Grimaldi, R., Kalia, M., and Eneroth, P. (1988c). "The opioid peptide sytems: their organization and role in volume transmission and neuroendocrine regulation," in Regulatory Roles of Opioid Peptides, eds P. Illes and C. Farsang (Weinheim: VCH), 33-68.

Fuxe, K., Agnati, L. F., Jacobsen, K., Hillion, J., Canals, M., Torvinen, M., Tinner-Staines, B., Staines, W., Rosin, D., Terasmaa, A., Popoli, P. Leo, G., Vergoni, V., Lluis, C., Ciruela, F., Franco, R., and Ferre, S. (2003). Receptor heteromerization in adenosine A2A receptor signaling: relevance for striatal function and Parkinson's disease. Neurology 61, S19-S23.

Fuxe, K., Agnati, L. F., and Mora, F. (2008a). The basal ganglia. Brain Res. Rev. 58, 1-482.

Fuxe, K., Marcellino, D., Guidolin, D. Woods, A. S., and Agnati, L. F. (2008b). Heterodimers and receptor mosaics of different types of Gprotein-coupled receptors. Physiology (Bethesda) 23, 322-332.

Fuxe, K., Marcellino, D., Rivera, A. Diaz-Cabiale, Z., Filip, M., Gago, B., Roberts, D. C., Langel, U., Genedani, S., Ferraro, L., De La Calle, A., Narvaez, J., Tanganelli, S., Woods, A., and Agnati, L. F. (2008c). Receptorreceptor interactions within receptor mosaics. Impact on neuropsychopharmacology. Brain Res. Rev. $58,415-452$.

Fuxe, K., Dahlstrom, A., Hoistad, M., Marcellino, D., Jansson, A. Rivera, A., Diaz-Cabiale, Z., Jacobsen, K., Tinner-Staines, B., Hagman, B., Leo, G., Staines, W., Guidolin, D., Kehr, J., Genedani, S., Belluardo, N., and Agnati, L. F. (2007a). From the Golgi-Cajal mapping to the transmitter-based characterization of the neuronal networks leading to two modes of brain communication: wiring and volume transmission. Brain Res. Rev. 55, 17-54.

Fuxe, K., Ferre, S., Genedani, S., Franco, R., and Agnati, L. F. (2007b). Adenosine receptor-dopamine receptor interactions in the basal ganglia and their relevance for brain function. Physiol. Behav. 92, 210-217.

Fuxe, K., Dahlstrom, A. B., Jonsson, G., Marcellino, D., Guescini, M., Dam, M., Manger, P., and Agnati, L. (2010a). The discovery of central monoamine neurons gave volume transmission to the wired brain. Prog. Neurobiol. 90, 82-100.

Fuxe, K., Marcellino, D., BorrotoEscuela, D. O., Frankowska, M., Ferraro, L., Guidolin, D., Ciruela, F., and Agnati, L. F. (2010b).
The changing world of G proteincoupled receptors: from monomers to dimers and receptor mosaics with allosteric receptor-receptor interactions. J. Recept. Signal Transduct. Res. 30, 272-283.

Fuxe, K., Marcellino, D., BorrotoEscuela, D. O., Guescini, M., Fernandez-Duenas, V., Tanganelli, S., Rivera, A., Ciruela, F., and Agnati, L. F. (2010c). Adenosine-dopamine interactions in the pathophysiology and treatment of CNS disorders. CNS Neurosci. Ther. 16, e18-e42.

Fuxe, K., Ferre, S., Zoli, M., and Agnati, L. F. (1998). Integrated events in central dopamine transmission as analyzed at multiple levels. Evidence for intramembrane adenosine $\mathrm{A} 2 \mathrm{~A} /$ dopamine D2 and adenosine A1/dopamine D1 receptor interactions in the basal ganglia. Brain Res. Brain Res. Rev. 26, 258-273.

Fuxe, K., Hokfelt, T., and Nilsson, O. (1967). Activity changes in the tubero-infundibular dopamine neurons of the rat during various states of the reproductive cycle. Life Sci. 6, 2057-2061.

Fuxe, K., Li, X. M., Tanganelli, S., Hedlund, P., O'Connor, W. T., Ferraro, L., Ungerstedt, U., and Agnati, L. F. (1995). Receptor-receptor interactions and their relevance for receptor diversity. Focus on neuropeptide/dopamine interactions. Ann. N. Y. Acad. Sci. 757, 365-376.

Fuxe, K., Marcellino, D., Woods, A. S., Giuseppina, L., Antonelli, T., Ferraro, L., Tanganelli, S., and Agnati, L. F. (2009). Integrated signaling in heterodimers and receptor mosaics of different types of GPCRs of the forebrain: relevance for schizophrenia. $J$. Neural Transm. 116, 923-939.

Fuxe, K., Rivera, A., Jacobsen, K. X., Hoistad, M., Leo, G., Horvath, T. L., Staines, W., De La Calle, A., and Agnati, L. F. (2005). Dynamics of volume transmission in the brain. Focus on catecholamine and opioid peptide communication and the role of uncoupling protein 2. J. Neural Transm. 112, 65-76.

Fuxe, K., and Ungerstedt, U. (1970a). "Histochemical, biochemical, and functional studies on central monoamine neurons after acute and chronic amphetamine administration," in Amphetamines and Related Compounds, eds E. Costa and S. Garattini (New York: Raven Press), 257-288.

Fuxe, K., Von Euler, G., Agnati, L. F., Merlo Pich, E., O'Connor,W. T., Tanganelli, S., Li, X. M., Tinner, B., Cintra, A., Carani, C., and Benfenati, F. (1992). Intramembrane interactions 
between neurotensin receptors and dopamine D2 receptors as a major mechanism for the neuroleptic-like action of neurotensin. Ann. N. Y. Acad. Sci. 668, 186-204.

Gago, B., Fuxe, K., Agnati, L., Penafiel, A., De La Calle, A., and Rivera, A. (2007). Dopamine D(4) receptor activation decreases the expression of mu-opioid receptors in the rat striatum. J. Comp. Neurol. 502, 358-366.

Gago, B., Suarez-Boomgaard, D., Fuxe, K., Brene, S., Reina-Sanchez, M. D., Rodriguez-Perez, L. M., Agnati, L. F., De La Calle, A., and Rivera, A. (2011). Effect of acute and continuous morphine treatment on transcription factor expression in subregions of the rat caudate putamen. Marked modulation by D4 receptor activation. Brain Res. 1407, 47-61.

George, S. R., and O'Dowd, B. F. (2007). A novel dopamine receptor signaling unit in brain: heterooligomers of D1 and D2 dopamine receptors. ScientificWorldJournal 7, 58-63.

Gerfen, C. R., and Surmeier, D. J. (2011). Modulation of striatal projection systems by dopamine. Annu. Rev. Neurosci. 34, 441-466.

Gisiger, V., and Stephens, H. R. (1988). Localization of the pool of G4 acetylcholinesterase characterizing fast muscles and its alteration in murine muscular dystrophy. J. Neurosci. Res. $19,62-78$.

Goin, J. C., and Nathanson, N. M. (2006). Quantitative analysis of muscarinic acetylcholine receptor homo- and heterodimerization in live cells: regulation of receptor down-regulation by heterodimerization. J. Biol. Chem. 281, 5416-5425.

Gras, C., Amilhon, B., Lepicard, E. M., Poirel, O., Vinatier, J., Herbin, M., Dumas, S., Tzavara, E. T., Wade, M. R., Nomikos, G. G., Hanoun, N., Saurini, F., Kemel, M. L., Gasnier, B., Giros, B., and El Mestikawy, S. (2008). The vesicular glutamate transporter VGLUT3 synergizes striatal acetylcholine tone. Nat. Neurosci. 11, 292-300.

Gruber, S. H., Nomikos, G. G., and Mathe, A. A. (2002). Effects of haloperidol and risperidone on neurotensin levels in brain regions and neurotensin efflux in the ventral striatum of the rat. Neuropsychopharmacology 26, 595-604.

Guescini, M., Leo, G., Genedani, S., Carone, C., Pederzoli, F., Ciruela, F., Guidolin, D., Stocchi, V., Mantuano, M., Borroto-Escuela, D. O., Fuxe, K., and Agnati, L. F. (2012). Microvesicle and tunneling nanotube mediated intercellular transfer of g-protein coupled receptors in cell cultures. Exp. Cell Res. 318, 603-613.

Haas, H., and Panula, P. (2003). The role of histamine and the tuberomamillary nucleus in the nervous system. Nat. Rev. Neurosci. 4, 121-130.

Hansson, A. C., Andersson, A., Tinner, B., Cui, X., Sommer, W., and Fuxe, K. (1998). Existence of striatal nerve cells coexpressing CCK(B) and D2 receptor mRNAs. Neuroreport 9, 2035-2038.

Harvey, C. D., and Svoboda, K. (2007). Locally dynamic synaptic learning rules in pyramidal neuron dendrites. Nature 450, 1195-1200.

Hasbi, A., O’Dowd, B. F., and George, S. R. (2011). Dopamine D1-D2 receptor heteromer signaling pathway in the brain: emerging physiological relevance. Mol. Brain 4, 26.

Hersch, S. M., Ciliax, B. J., Gutekunst, C. A., Rees, H. D., Heilman, C. J., Yung, K. K., Bolam, J. P., Ince, E., Yi, H., and Levey, A. I. (1995). Electron microscopic analysis of D1 and D2 dopamine receptor proteins in the dorsal striatum and their synaptic relationships with motor corticostriatal afferents. J. Neurosci. 15, 5222-5237.

Hersch, S. M., Yi, H., Heilman, C. J., Edwards, R. H., and Levey, A. I. (1997). Subcellular localization and molecular topology of the dopamine transporter in the striatum and substantia nigra. J. Comp. Neurol. 388, 211-227.

Hillion, J., Canals, M., Torvinen, M., Casado, V., Scott, R., Terasmaa, A., Hansson, A., Watson, S., Olah, M. E., Mallol, J., Canela, E. I., Zoli, M., Agnati, L. F., Ibanez, C. F., Lluis, C., Franco, R., Ferre, S., and Fuxe, K. (2002). Coaggregation, cointernalization, and codesensitization of adenosine $\mathrm{A} 2 \mathrm{~A}$ receptors and dopamine D2 receptors. J. Biol. Chem. 277, 18091-18097.

Hnasko, T. S., Chuhma, N., Zhang, H., Goh, G. Y., Sulzer, D., Palmiter, R. D., Rayport, S., and Edwards, R. H. (2010). Vesicular glutamate transport promotes dopamine storage and glutamate corelease in vivo. Neuron 65, 643-656.

Hnasko, T. S., Sotak, B. N., and Palmiter, R. D. (2005). Morphine reward in dopamine-deficient mice. Nature 438, 854-857.

Hoistad, M., Chen, K. C., Nicholson, C., Fuxe, K., and Kehr, J. (2002). Quantitative dual-probe microdialysis: evaluation of $[3 \mathrm{H}]$ mannitol diffusion in agar and rat striatum. $J$. Neurochem. 81, 80-93.
Hoistad, M., Samskog, J., Jacobsen, K. X., Olsson, A., Hansson, H. A. Brodin, E., and Fuxe, K. (2005). Detection of beta-endorphin in the cerebrospinal fluid after intrastriata microinjection into the rat brain Brain Res. 1041, 167-180.

Hökfelt, T., Fuxe, K., and Pernow, B. (1986). Coexistence of Neuronal Messengers: A New Principle in Chemical Transmission, in Progress in Brain Research, Vol. 68 (New York: Elsevier), 1-403.

Jansson, A., Descarries, L., CorneaHebert, V., Riad, M., Verge, D., Bancila, M., Agnati, L. F., and Fuxe, K. (2002). "Transmitter-receptor mistaches in central dopamine serotonin and neuropeptide systems," in The Neuronal Environment: Brain Homeostasis in Health and Disease, ed. W. Walz (Totowa, NJ: Humana Press), 83-107.

Jansson, A., Goldstein, M., Tinner, B., Zoli, M., Meador-Woodruff, J. H., Lew, J. Y., Levey, A. I., Watson, S., Agnati, L. F., and Fuxe, K. (1999). On the distribution patterns of D1, D2, tyrosine hydroxylase and dopamine transporter immunoreactivities in the ventral striatum of the rat. $\mathrm{Neu}$ roscience $89,473-489$.

Jansson, A., Tinner, B., Bancila, M. Verge, D., Steinbusch, H. W., Agnati, L. F., and Fuxe, K. (2001). Relationships of 5-hydroxytryptamine immunoreactive terminal-like varicosities to 5-hydroxytryptamine-2A receptor-immunoreactive neuronal processes in the rat forebrain. J. Chem. Neuroanat. 22, 185-203.

Juhasz, J. R., Hasbi, A., Rashid, A. J., So, C. H., George, S. R., and O'Dowd B. F. (2008). Mu-opioid receptor heterooligomer formation with the dopamine D1 receptor as directly visualized in living cells. Eur. J. Pharmacol. 581, 235-243.

Kawaguchi, Y. (1995). Physiological subgroups of nonpyramidal cells with specific morphological characteristics in layer II/III of rat frontal cortex. J. Neurosci. 15, 2638-2655.

Kenakin, T., Agnati, L. F., Caron, M., Fredholm, B., Guidoli, D., Kobilka, B., Lefkowitz, R. W., Lohse, M., Woods, A., and Fuxe, K. (2010). International Workshop at the Nobel Forum, Karolinska Institutet on $\mathrm{G}$ protein-coupled receptors: finding the words to describe monomers, oligomers, and their molecular mechanisms and defining their meaning. Can a consensus be reached? J. Recept. Signal Transduct. Res. 30, 284-286.

Laruelle, M. (2000). Imaging synaptic neurotransmission with in vivo binding competition techniques: a critical review. J. Cereb. Blood Flow Metab. 20, 423-451.

Lee, F. J., Wang, Y. T., and Liu, F. (2005). Direct receptor cross-talk can mediate the modulation of excitatory and inhibitory neurotransmission by dopamine. J. Mol. Neurosci. 26, 245-252.

Lee, F. J., Xue, S., Pei, L., Vukusic, B., Chery, N., Wang, Y., Wang, Y. T., Niznik, H. B., Yu, X. M., and Liu, F. (2002). Dual regulation of NMDA receptor functions by direct protein-protein interactions with the dopamine D1 receptor. Cell 111, 219-230.

Levey, A. I., Hersch, S. M., Rye, D. B., Sunahara, R. K., Niznik, H. B., Kitt, C. A., Price, D. L., Maggio, R., Brann, M. R., and Ciliax, B. J. (1993). Localization of D1 and D2 dopamine receptors in brain with subtypespecific antibodies. Proc. Natl. Acad. Sci. U.S.A. 90, 8861-8865.

Li, X. M., Ferraro, L., Tanganelli, S., O'Connor, W. T., Hasselrot, U., Ungerstedt, U., and Fuxe, K. (1995a). Neurotensin peptides antagonistically regulate postsynaptic dopamine D2 receptors in rat nucleus accumbens: a receptor binding and microdialysis study. J. Neural Transm. Gen. Sect. 102, 125-137.

Li, X. M., Hedlund, P. B., and Fuxe, K. (1995b). Cholecystokinin octapeptide in vitro and ex vivo strongly modulates striatal dopamine D2 receptors in rat forebrain sections. Eur. J. Neurosci. 7, 962-971.

Li, X. M., Hedlund, P. B., Agnati, L. F., and Fuxe, K. (1994a). Dopamine D1 receptors are involved in the modulation of D2 receptors induced by cholecystokinin receptor subtypes in rat neostriatal membranes. Brain Res. 650, 289-298.

Li, X. M., Hedlund, P. B., and Fuxe, K. (1994b). Strong effects of NT/NN peptides on DA D2 receptors in rat neostriatal sections. Neuroreport 5 , 1621-1624.

Liu, F., Wan, Q., Pristupa, Z. B., Yu, X. M., Wang, Y. T., and Niznik, H. B. (2000). Direct proteinprotein coupling enables crosstalk between dopamine D5 and gamma-aminobutyric acid A receptors. Nature 403, 274-280.

Liu, X. Y., Chu, X. P., Mao, L. M., Wang, M., Lan, H. X., Li, M. H., Zhang, G. C., Parelkar, N. K., Fibuch, E. E., Haines, M., Neve, K. A., Liu, F., Xiong, Z. G., and Wang, J. Q. (2006). Modulation of D2R-NR2B interactions in response to cocaine. Neuron 52, 897-909. 
Lukasiewicz, S., Polit, A., KedrackaKrok, S., Wedzony, K., Mackowiak, M., and Dziedzicka-Wasylewska, M. (2010). Hetero-dimerization of serotonin 5-HT(2A) and dopamine $\mathrm{D}(2)$ receptors. Biochim. Biophys. Acta 1803, 1347-1358.

Lundberg, J. (1991). "Volume transmission by coreleased peptides in the autonomic nervous system," in Volume Transmission in the Brain, eds K. Fuxe and L. Agnati (Stockholm: Raven Press), 425-432.

MacLeod, R. M., and Lehmeyer, J. E. (1974). Studies on the mechanism of the dopamine-mediated inhibition of prolactin secretion. Endocrinology 94, 1077-1085.

MacMillan, S. J., Mark, M. A., and Duggan, A. W. (1998). The release of beta-endorphin and the neuropeptide-receptor mismatch in the brain. Brain Res. 794, 127-136.

Marcellino, D., Carriba, P., Filip, M., Borgkvist, A., Frankowska, M., Bellido, I., Tanganelli, S., Muller, C. E., Fisone, G., Lluis, C., Agnati, L. F., Franco, R., and Fuxe, K. (2008). Antagonistic cannabinoid $\mathrm{CB} 1 /$ dopamine D2 receptor interactions in striatal CB1/D2 heteromers. A combined neurochemical and behavioral analysis. Neuropharmacology 54, 815-823.

Marcellino, D., Kehr, J., Agnati, L. F., and Fuxe, K. (2011). Increased affinity of dopamine for $\mathrm{D}(2)$-like versus $\mathrm{D}(1)$-like receptors. Relevance for volume transmission in interpreting PET findings. Synapse. doi: 10.1002/syn.21501. [Epub ahead of print].

Martin, A. B., Fernandez-Espejo, E., Ferrer, B., Gorriti, M. A., Bilbao, A., Navarro, M., Rodriguez De Fonseca, F., and Moratalla, R. (2008). Expression and function of CB1 receptor in the rat striatum: localization and effects on D1 and D2 dopamine receptor-mediated motor behaviors. Neuropsychopharmacology 33, 1667-1679.

Moreno, E., Hoffmann, H., GonzalezSepulveda, M., Navarro, G., Casado, V., Cortes, A., Mallol, J., Vignes, M., Mccormick, P. J., Canela, E. I., Lluis, C., Moratalla, R., Ferre, S., Ortiz, J., and Franco, R. (2010). Dopamine D1-histamine H3 receptor heteromers provide a selective link to MAPK signaling in GABAergic neurons of the direct striatal pathway. J. Biol. Chem. 286, 5846-5854.

Morino, P., Herrera-Marschitz, M., Castel, M. N., Ungerstedt, U., Varro, A., Dockray, G., and Hokfelt, T. (1994). Cholecystokinin in cortico-striatal neurons in the rat: immunohistochemical studies at the light and electron microscopical level. Eur. J. Neurosci. 6, 681-692.

Narushima, M., Uchigashima, M., Fukaya, M., Matsui, M., Manabe, T., Hashimoto, K., Watanabe, M., and Kano, M. (2007). Tonic enhancement of endocannabinoid-mediated retrograde suppression of inhibition by cholinergic interneuron activity in the striatum. J. Neurosci. 27, 496-506.

Newman-Tancredi, A., AudinotBouchez, V., Gobert, A., and Millan, M. J. (1997). Noradrenaline and adrenaline are high affinity agonists at dopamine D4 receptors. Eur. J. Pharmacol. 319, 379-383.

Nicholson, C., and Sykova, E. (1998). Extracellular space structure revealed by diffusion analysis. Trends Neurosci. 21, 207-215.

Ogren, S. O., and Fuxe, K. (1988). D1and D2-receptor antagonists induce catalepsy via different efferent striatal pathways [corrected]. Neurosci. Lett. 85, 333-338.

Okubo, Y., and Iino, M. (2011). Visualization of glutamate as a volume transmitter. J. Physiol. (Lond.) 589, 481-488.

Okubo, Y., Sekiya, H., Namiki, S., Sakamoto, H., Iinuma, S., Yamasaki, M., Watanabe, M., Hirose, K., and lino, M. (2010). Imaging extrasynaptic glutamate dynamics in the brain. Proc. Natl. Acad. Sci. U.S.A. 107, 6526-6531.

Oldenburg, I. A., and Ding, J. B. (2011). Cholinergic modulation of synaptic integration and dendritic excitability in the striatum. Curr. Opin. Neurobiol. 21, 425-432.

Ozog, M. A., Siushansian, R., and Naus, C. C. (2002). Blocked gap junctional coupling increases glutamateinduced neurotoxicity in neuronastrocyte co-cultures. J. Neuropathol. Exp. Neurol. 61, 132-141.

Perreault, M. L., Hasbi, A., Alijaniaram, M., Fan, T., Varghese, G., Fletcher, P. J., Seeman, P., O’Dowd, B. F., and George, S. R. (2010). The dopamine D1-D2 receptor heteromer localizes in dynorphin/enkephalin neurons: increased high affinity state following amphetamine and in schizophrenia. J. Biol. Chem. 285, 36625-36634.

Piomelli, D. (2003). The molecular logic of endocannabinoid signalling. Nat. Rev. Neurosci. 4, 873-884.

Pisani, A., Bernardi, G., Ding, J., and Surmeier, D. J. (2007). Re-emergence of striatal cholinergic interneurons in movement disorders. Trends $\mathrm{Neu}$ rosci. 30, 545-553.
Popoli, P., Pezzola, A., Torvinen, M., Reggio, R., Pintor, A., Scarchilli, L., Fuxe, K., and Ferre, S. (2001). The selective $\mathrm{mGlu}(5)$ receptor agonist CHPG inhibits quinpirole-induced turning in 6-hydroxydopaminelesioned rats and modulates the binding characteristics of dopamine $\mathrm{D}(2)$ receptors in the rat striatum: interactions with adenosine $\mathrm{A}(2 \mathrm{a})$ receptors. Neuropsychopharmacology 25 505-513.

Rice, M. E., and Cragg, S. J. (2008). Dopamine spillover after quantal release: rethinking dopamine transmission in the nigrostriatal pathway. Brain Res. Rev. 58, 303-313.

Rivera, A., Agnati, L. F., Horvath, T. L., Valderrama, J. J., De La Calle, A., and Fuxe, K. (2006). Uncoupling protein $2 / 3$ immunoreactivity and the ascending dopaminergic and noradrenergic neuronal systems: relevance for volume transmission. $\mathrm{Neu}$ roscience 137, 1447-1461.

Rivera, A., Penafiel, A., Megias, M., Agnati, L. F., Lopez-Tellez, J. F., Gago, B., Gutierrez, A., De La Calle, A., and Fuxe, K. (2008). Cellular localization and distribution of dopamine $\mathrm{D}(4)$ receptors in the rat cerebral cortex and their relationship with the cortical dopaminergic and noradrenergic nerve terminal networks. Neuroscience 155 997-1010.

Rocheville, M., Lange, D. C., Kumar, U., Patel, S. C., Patel, R. C., and Patel, Y. C. (2000). Receptors for dopamine and somatostatin: formation of hetero-oligomers with enhanced functional activity. Science 288, 154-157.

Schiffmann, S. N., and Vanderhaeghen, J. J. (1993). Adenosine A2 receptors regulate the gene expression of striatopallidal and striatonigral neurons. J. Neurosci. 13, 1080-1087.

Schools, G. P., Zhou, M., and Kimelberg, H. K. (2006). Development of gap junctions in hippocampal astrocytes: evidence that whole cell electrophysiological phenotype is an intrinsic property of the individual cell. J. Neurophysiol. 96, 1383-1392.

Schwarcz, R., and Pellicciari, R. (2002). Manipulation of brain kynurenines: glial targets, neuronal effects, and clinical opportunities. J. Pharmacol. Exp. Ther. 303, 1-10.

Sebastiao, A. M., and Ribeiro, J. A. (2000). Fine-tuning neuromodulation by adenosine. Trends Pharmacol. Sci. 21, 341-346.

Seguela, P., Watkins, K. C., Geffard, M., and Descarries, L. (1990).
Noradrenaline axon terminals in adult rat neocortex: an immunocytochemical analysis in serial thin sections. Neuroscience 35, 249-264.

Seneca, N., Finnema, S. J., Farde, L., Gulyas, B., Wikstrom, H. V., Halldin C., and Innis, R. B. (2006). Effect of amphetamine on dopamine D2 receptor binding in nonhuman primate brain: a comparison of the agonist radioligand [11C]MNPA and antagonist [11C]raclopride. Synapse 59, 260-269.

Sesack, S. R., Aoki, C., and Pickel, V. M. (1994). Ultrastructural localization of D2 receptor-like immunoreactivity in midbrain dopamine neurons and their striatal targets. J. Neurosci. 14, 88-106.

Smiley, J. F., Levey, A. I., Ciliax, B. J., and Goldman-Rakic, P. S. (1994). D1 dopamine receptor immunoreactivity in human and monkey cerebral cortex: predominant and extrasynaptic localization in dendritic spines. Proc. Natl. Acad. Sci. U.S.A. 91, 5720-5724.

Smiley, J. F., Morrell, F., and Mesulam, M. M. (1997). Cholinergic synapses in human cerebral cortex: an ultrastructural study in serial sections. Exp. Neurol. 144, 361-368.

Smiley, J. F., Williams, S. M., Szigeti, K., and Goldman-Rakic, P. S. (1992). Light and electron microscopic characterization of dopamineimmunoreactive axons in human cerebral cortex. J. Comp. Neurol. 321, 325-335.

Surmeier, D. J., Ding, J., Day, M., Wang, Z., and Shen, W. (2007). D1 and D2 dopamine-receptor modulation of striatal glutamatergic signaling in striatal medium spiny neurons. Trends Neurosci. 30, 228-235.

Tanganelli, S., Antonelli, T., Tomasini, M. C., Beggiato, S., Fuxe, K., and Ferraro, L. (2012). Relevance of dopamine $\mathrm{D}(2)$ /neurotensin NTS1 and NMDA/neurotensin NTS1 receptor interaction in psychiatric and neurodegenerative disorders. Curr. Med. Chem. 19, 304-316.

Tanganelli, S., Fuxe, K., Antonelli, T., O'Connor, W. T., and Ferraro, L. (2001). Cholecystokinin/ dopamine/GABA interactions in the nucleus accumbens: biochemical and functional correlates. Peptides 22, 1229-1234.

Tanganelli, S., Fuxe, K., Von Euler, G., Eneroth, P., Agnati, L. F., and Ungerstedt, U. (1990). Changes in pituitary-adrenal activity affect the apomorphine- and cholecystokinin8 -induced changes in striatal 
dopamine release using microdialysis. J. Neural Transm. Gen. Sect. 81, 183-194.

Tanganelli, S., Li, X. M., Ferraro, L., Von Euler, G., O'Connor, W. T., Bianchi, C., Beani, L., and Fuxe, K. (1993). Neurotensin and cholecystokinin octapeptide control synergistically dopamine release and dopamine $\mathrm{D} 2$ receptor affinity in rat neostriatum. Eur. J. Pharmacol. 230, 159-166.

Tanganelli, S., O'Connor, W. T., Ferraro, L., Bianchi, C., Beani, L., Ungerstedt, U., and Fuxe, K. (1994). Facilitation of GABA release by neurotensin is associated with a reduction of dopamine release in rat nucleus accumbens. Neuroscience 60, 649-657.

Tanganelli, S., Von Euler, G., Fuxe, K., Agnati, L. F., and Ungerstedt, U. (1989). Neurotensin counteracts apomorphine-induced inhibition of dopamine release as studied by microdialysis in rat neostriatum. Brain Res. 502, 319-324.

Tepper, J. M., Abercrombie, E. D., and Bolam, J. P. (2007). Basal ganglia macrocircuits. Prog. Brain Res. 160, 3-7.

Tepper, J. M., Wilson, C. J., and Koos, T. (2008). Feedforward and feedback inhibition in neostriatal GABAergic spiny neurons. Brain Res. Rev. 58, 272-281.
Torvinen, M., Gines, S., Hillion, J., Latini, S., Canals, M., Ciruela, F., Bordoni, F., Staines, W., Pedata, F., Agnati, L. F., Lluis, C., Franco, R., Ferre, S., and Fuxe, K. (2002). Interactions among adenosine deaminase, adenosine $\mathrm{A}(1)$ receptors and dopamine $\mathrm{D}(1)$ receptors in stably cotransfected fibroblast cells and neurons. Neuroscience 113, 709-719.

Trueta, C., Mendez, B., and De-Miguel, F. F. (2003). Somatic exocytosis of serotonin mediated by L-type calcium channels in cultured leech neurones. J. Physiol. (Lond.) 547, 405-416.

Uchigashima, M., Narushima, M., Fukaya, M., Katona, I., Kano, M., and Watanabe, M. (2007). Subcellular arrangement of molecules for 2-arachidonoyl-glycerol-mediated retrograde signaling and its physiological contribution to synaptic modulation in the striatum. J. Neurosci. 27, 3663-3676.

Ungerstedt, U., Butcher, L. L., Butcher, S. G., Anden, N. E., and Fuxe, K. (1969). Direct chemical stimulation of dopaminergic mechanisms in the neostriatum of the rat. Brain Res. 14, 461-471.

Vizi, E. S. (1980). Non-synaptic modulation of transmitter release: pharmacological implications. Trends Pharmacol. Sci. 1, 172-175.
Vizi, E. S., Kiss, J. P., and Lendvai, B. (2004). Nonsynaptic communication in the central nervous system. Neurochem. Int. 45 , 443-451.

von Euler, G. (1991). Biochemical characterization of the intramembrane interaction between neurotensin and dopamine D2 receptors in the rat brain. Brain Res. 561 , 93-98.

Von Euler, G., and Fuxe, K. (1987). Neurotensin reduces the affinity of $\mathrm{D}-2$ dopamine receptors in rat striatal membranes. Acta Physiol. Scand. 131, 625-626.

Wang, Z., Kai, L., Day, M., Ronesi, J., Yin, H. H., Ding, J., Tkatch, T., Lovinger, D. M., and Surmeier, D. J. (2006). Dopaminergic control of corticostriatal long-term synaptic depression in medium spiny neurons is mediated by cholinergic interneurons. Neuron 50, 443-452.

Yung, K. K., Bolam, J. P., Smith, A. D. Hersch, S. M., Ciliax, B. J., and Levey, A. I. (1995). Immunocytochemical localization of D1 and D2 dopamine receptors in the basal ganglia of the rat: light and electron microscopy. Neuroscience 65, 709-730.

Zoli, M., and Agnati, L. F. (1996). Wiring and volume transmission in the central nervous system: the concept of closed and open synapses. Prog. Neurobiol. 49, 363-380.
Conflict of Interest Statement: The authors declare that the research was conducted in the absence of any commercial or financial relationships that could be construed as a potential conflict of interest.

Received: 24 March 2012; paper pending published: 12 April 2012; accepted: 23 April 2012; published online: 04 June 2012.

Citation: Fuxe K, Borroto-Escuela DO, Romero-Fernandez W, Diaz-Cabiale $Z$, Rivera A, Ferraro L, Tanganelli $S$, Tarakanov AO, Garriga $P$, Narváez $J A$, Ciruela F, Guescini $M$ and Agnat LF (2012) Extrasynaptic neurotransmission in the modulation of brain function. Focus on the striatal neuronalglial networks. Front. Physio. 3:136. doi: 10.3389/fphys.2012.00136

This article was submitted to Frontiers in Membrane Physiology and Biophysics, a specialty of Frontiers in Physiology.

Copyright (C) 2012 Fuxe, Borroto-Escuela,

Romero-Fernandez, Diaz-Cabiale, Rivera, Ferraro, Tanganelli, Tarakanov, Garriga, Narváez, Ciruela, Guescini and Agnati. This is an open-access article distributed under the terms of the Creative Commons Attribution Non Commercial License, which permits non-commercial use, distribution, and reproduction in other forums, provided the original authors and source are credited. 